This item was submitted to Loughborough's Research Repository by the author.

Items in Figshare are protected by copyright, with all rights reserved, unless otherwise indicated.

\title{
Experimental analysis of the scaled DTU10MW TLP floating wind turbine with different control strategies
}

\section{PLEASE CITE THE PUBLISHED VERSION}

https://doi.org/10.1016/j.renene.2020.03.145

\section{PUBLISHER}

Elsevier BV

VERSION

AM (Accepted Manuscript)

\section{PUBLISHER STATEMENT}

This paper was accepted for publication in the journal Renewable Energy and the definitive published version is available at https://doi.org/10.1016/j.renene.2020.03.145.

\section{LICENCE}

CC BY-NC-ND 4.0

\section{REPOSITORY RECORD}

Madsen, FJ, TRL Nielsen, Taeseong Kim, H Bredmose, A Pegalajar-Jurado, RF Mikkelsen, AK Lomholt, M Borg, M Mirzaei, and P Shin. 2020. "Experimental Analysis of the Scaled DTU10MW TLP Floating Wind Turbine with Different Control Strategies". Loughborough University. https://hdl.handle.net/2134/13604072.v1. 


\title{
Experimental analysis of the scaled DTU10MW TLP floating wind turbine with different control strategies
}

\author{
FJ Madsen ${ }^{1}$, TRL Nielsen ${ }^{1}$, T Kim ${ }^{1,2}$, H Bredmose $^{1}$, A Pegalajar-Jurado ${ }^{1}$, RF \\ Mikkelsen $^{1}$, AK Lomholt ${ }^{1}$, M Borg ${ }^{1,3}$, M Mirzaei $^{1,4}$ and P Shin ${ }^{5}$ \\ 1 DTU Wind Energy, Kgs. Lyngby, Denmark \\ 2 Centre for Renewable Energy Systems Technology (CREST), Wolfson School of \\ Mechanical, Electrical and Manufacturing Engineering, Loughborough University, \\ Loughborough, LE11 3TU, UK \\ ${ }^{3}$ Borg RED, Malta \\ 4 Vestas, Aarhus/Copenhagen, Denmark \\ 5 Wind Energy Laboratory, Jeju Global Research Center, Korea Institute of Energy \\ Research (KIER), Jeju, Korea
}

\section{Abstract}

The experimental testing of a Tension Leg Platform (TLP) floating wind turbine at 1:60 scale in wind and waves with a pitch-regulated 10MW wind turbine is presented. The floating wind turbine was tested with three different control configurations: two closed-loop controllers and one open-loop controller. The experimental setup and program is described in this paper, and system identification and the responses of the floater to hydrodynamic loading are analysed and compared for the different control strategies. It was observed that negative aerodynamic damping for the onshore controller resulted in high oscillations in blade pitch, yielding an increased response in surge for all wave types. It was also observed that the surge motion governed the mooring line tensions, thus the onshore controller yielded the highest tensions in the front mooring line. Further the shutdown cases of the offshore controller led to larger surge displacement when the shutdown was initialized right before the wave impact.

Keywords: Floating wind turbine; scale model test; control; dynamic response.

\section{Introduction}

European Union (EU) made a plan to meet 20 percent energy consumption from renewable energy source by 2020 in 2006 [1]. A new target of at least 27 percent of EU's energy consumption from renewable energy by 2030 has been 
agreed in 2014. In order to meet the target the share of renewable energy in the electricity would increase from 21 persent to 45 persent by 2030 [2]. The considered renewable sources are wind, solar, wave, tidal, hydro, geothermal, biomass, etc. Among them wind energy has became the most promising renewable energy source. The global wind energy installed capacity reached $591 \mathrm{GW}$ in 2018 and in total 51.3GW of new wind farm capacity was installed in 2018, where $4.49 \mathrm{GW}$, which is approximately 20 percent of growth rate, was covered by offshore wind energy. Especially in Europe in total 409 new offshore wind turbines were connected to the grid in 2018 and has approximately $18.5 \mathrm{GW}$ installed capacity in the offshore sector [3]. The next step of offshore wind energy will be "DEEP WATER", i.e. water depths greater than $50 \mathrm{~m}$, meaning that floating wind turbine concepts must be developed. In response to this challenge the first commercial floating wind farm, Hywind Scotland Pilot Park, has been successfully installed and operated since 2017. Here the Hywind type spar buoy floater is applied with a 6MW SWT-6.0-154 wind turbine. However, the technology is still at early stage to achieve commercial and large-scale deployment. It requires the technological breakthroughs from wind turbines, control system, foundations, mooring and anchors, electrical infrastructures, installations, O\&M, design standard, design tools, etc. [4], [5].

There are large efforts to reduce risks of technology challenges and to identify innovations through the Floating Wind Joint Industry Project which is a collaborative R\&D project. From this project, the knowledge of the key technology challenges and innovation needs for electrical systems, mooring systems, infrastructure and logistics are investigated [6]. Additionally, the second phase of the project, which aims to build knowledge on wind turbine requirements, foundation scaling, installation and maintenance, monitoring and inspection, is on-going. Furthermore, research on developing floating wind turbine system design tools has been conducted and the developed numerical design tools are verified against other numerical results [7], [8]. Since floating wind turbine concepts are in the prototype stage there are not enough experimental data to use for code validations. Recently, few experimental studies with small scale floating wind turbine concepts have been performed [9]-[11]. Only few experimental tests considered matching the aerodynamic thrust and controlling blade pitch on the rotor. From [9] and [11] it is clearly seen how different controller settings affect the floating wind turbine responses. DTU also demonstrated small scaled floating wind turbine basin tests with different types of floater designs and blade pitch control [12]-[15].

This paper extended the one of previous DTU experimental test performed by Hansen and Laugesen [16] by including a newly designed TLP floater and active blade pitch control. The small scale experimental tests are challenging, because of contrasting physical scaling laws for aerodynamic and hydrodynamic loads. In addition, the reproduced environmental conditions will have an impact on the relevant dynamics and loading captured in the laboratory tests. In this paper a 1:60 scaled DTU10MW Reference Wind Turbine model, where the rotor was redesigned to deliver the right Froude scaled thrust at the low Reynolds number [17], is applied with the basic DTU Wind Energy controller [18]. The 
main purpose of this test campaign is to understand dynamic responses governed by wave, aerodynamics, and control system. Moreover, the test results are able to be used to validate numerical tools for a floating wind turbine system design. Therefore the tests are conducted to establish a data set in a number of wave climates such as regular, irregular, and focused wave groups, both with and without wind. Additionally, emergency shoutdown events with extreme wave condition, focused wave, were tested to analyze large surge effects condition driven by controller.

In the following the experimental setup during the test campaign will be described followed by a section on how the DTU Wind Energy controller was implemented. Next a validation of wind and waves, together with test and corrections on the performance of rotor thrust and decay tests are presented. Selected results highlighting the difference in behaviour of the floating wind turbine is shown based on three controller versions. This will be treated in both regular, irregular and focused waves, where the latter includes shutdown cases of the turbine.

\section{Model concept}

The TLP concept, developed by Korea Institute of Energy Research (KIER), consists of a floater body with a slender transition piece connecting the tower base to the floater body. Three outgoing spokes are mounted on the floater body, where the taunt mooring lines are attached. The stability of the concept is achieved through the excess buoyancy of the platform, thus the tension in the mooring lines. Figure 1 shows the model-scaled floating wind turbine.

\subsection{The 1:60 scale physical model}

A full scale TLP was designed by KIER based on the Ultimate Limit State (ULS) loads on the DTU 10MW Reference Wind Turbine (RWT) at the tower base. A 1:60 scaled model of the TLP concept was then developed based on the full-scale design to support the scaled DTU 10MW Reference Wind Turbine (RWT) [19] for the experimental campaign [20].

As in the previous test campaigns ([14],[21]), the Froude scaling law, with a geometric scaling ratio of 1:60, was applied to create the physical scaled model, following the work of [10] and [22]. It is known that the surface waves are primarily governed by the Froude number, $F r$, and hence it is common practice to preserve this number in model tests of offshore structures and floating bodies.

The key parameters of the DTU 10MW RWT, as described in [19], were Froude-scaled with the length scale ratio of $S r=60$. It introduces a significant issue that a geometrical scaling of the rotor will not give the correct aerodynamic performance of the blades due to the large dissimilitude in Reynolds number, $R e$, since the rotor aerodynamics are mainly governed by $R e$. This will lead to a reduction in the aerodynamic thrust and mechanical power, where especially the first is of great importance for the overall dynamics of the floating wind turbine. Hence, the rotor was redesigned in model scale using a steady thrust-matched 
rotor design, in order to deliver the right thrust at the low Re. Moreover effort was put into matching the tip speed ratio correctly and scaling the mass of the blades. The work of designing the thrust-matched blades is described in [17] and is characterized by an increase in chord length of $75 \%$ to achieve the needed lift at the low Re. This scaled rotor is identical to the one applied in previous campaigns ([14],[21]) and the manufacturing process is described in [16].

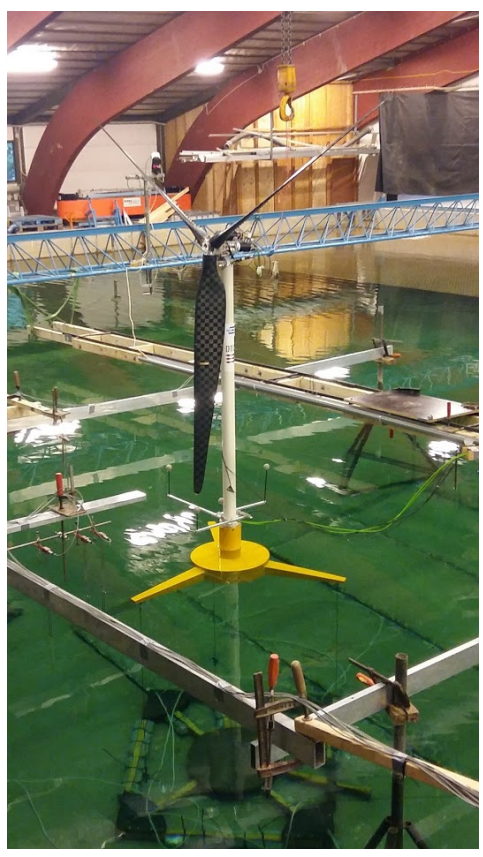

(a)

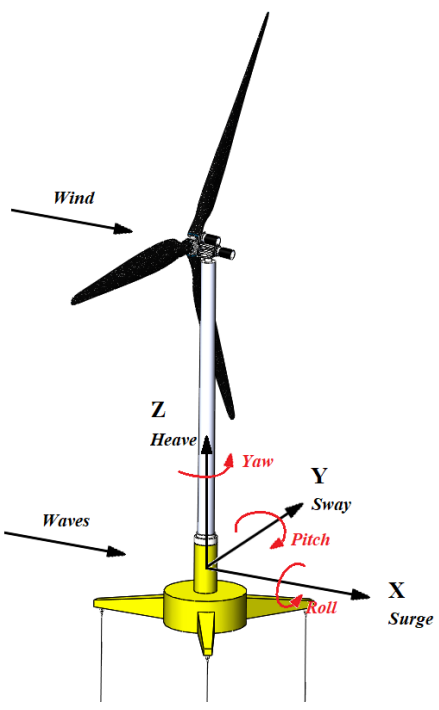

(b)

Figure 1: The TLP floating wind turbine concept. (a): the full TLP floating wind turbine model. (b): the global coordinate system and degrees of freedom of the floating wind turbine.

The hub and nacelle of the scaled wind turbine model is much more simple in its composition compared to full scale, as the number of components is reduced significantly. The main functions of the hub and nacelle are to contain the motors, for control torque and blade pitch, whilst limiting the model weight, since the Froude scaling impose strong limitations on the allowable structural mass in model scale. Two JVL MAC050 servomotors were used, one for torque control and one for blade pitch control. More details about the nacelle and hub system are described in [14].

Table 1 and 2 provide the main properties of the model scaled system. The corresponding full scale values of the model dimensions and masses can be obtained by multiplying the model scale values with the scaling factors $\frac{\rho_{p}}{\rho_{m}} S r$ and $\frac{\rho_{p}}{\rho_{m}} S r^{3}$ respectively, driven by the Froude scaling method, where $\rho_{p}$ and $\rho_{m}$ are the water densities in full and model scale respectively. The details on the 
scaling method are descirbed in [22]. The mooring lines used in this study were Dyneema ${ }^{\circledR}$ fiber ropes with diameter of $2.2 \mathrm{~mm}$ and breaking load of around $990 \mathrm{~kg}$, due to the high tensile strength to weight ratio. The stiffness of the mooring lines was measured to be $E A_{\text {moor }}=97.86 \cdot 10^{3} \mathrm{~N}$.

Table 1: The scaled TLP wind turbine masses.

\begin{tabular}{lcc}
\hline Element & Symbol & Model scale value \\
\hline Nacelle + hub mass & $m_{\text {nacelle }}+m_{\text {hub }}$ & $2.896 \mathrm{~kg}$ \\
Blade mass & $m_{\text {blade }}$ & $0.200 \mathrm{~kg}$ \\
Tower mass & $m_{\text {tower }}$ & $2.250 \mathrm{~kg}$ \\
Transition piece mass & $m_{\text {trans, } \text { dry }}$ & $2.400 \mathrm{~kg}$ \\
Floater mass & $m_{\text {float }}$ & $9.900 \mathrm{~kg}$ \\
Spoke mass & $m_{\text {spoke }}$ & $1.400 \mathrm{~kg}$ \\
\hline Total model mass & $m_{\text {tot }}$ & $22.246 \mathrm{~kg}$ \\
\hline
\end{tabular}

Table 2: The scaled TLP wind turbine dimensions.

\begin{tabular}{lcc}
\hline Dimension & Symbol & Model scale value \\
\hline Foundation & & \\
\hline Floater diameter & $D_{\text {float }}$ & $500 \mathrm{~mm}$ \\
Floater height & $h_{\text {float }}$ & $200 \mathrm{~mm}$ \\
Floater thickness & $t_{\text {float }}$ & $5 \mathrm{~mm}$ \\
Transition piece diameter & $D_{\text {trans }}$ & $138 \mathrm{~mm}$ \\
Transition piece height & $h_{\text {trans }}$ & $300 \mathrm{~mm}$ \\
Transition piece thickness & $t_{\text {trans }}$ & $5 \mathrm{~mm}$ \\
Spoke root area & $w_{r, \text { spoke }} \cdot h_{r, \text { spoke }}$ & $100 \mathrm{~mm} \cdot 133 \mathrm{~mm}$ \\
Spoke tip area & $w_{t, \text { spoke }} \cdot h_{t, \text { spoke }}$ & $50 \mathrm{~mm} \cdot 42 \mathrm{~mm}$ \\
Spoke length & $l_{\text {spoke }}$ & $500 \mathrm{~mm}$ \\
Spoke thickness & $t_{\text {spoke }}$ & $5 \mathrm{~mm}$ \\
\hline Mooring lines & & \\
\hline Fairlead position from root of spoke & $l_{f}$ & $450 \mathrm{~mm}$ \\
Mooring line diameter & $D_{\text {moor }}$ & $2.2 \mathrm{~mm}$ \\
Water depth & $h$ & $3000 \mathrm{~mm}$ \\
\hline Hub & & \\
\hline Rotor diameter & $D_{\text {rotor }}$ & $2972 \mathrm{~mm}$ \\
Blade length & $l_{\text {blade }}$ & $1440 \mathrm{~mm}$ \\
Hub height o. MWL & $h_{\text {hub }}$ & $1870 \mathrm{~mm}$ \\
\hline Tower & & \\
\hline Tower diameter & $D_{\text {tower }}$ \\
Tower height & $h_{\text {tower }}$ & $1682 \mathrm{~mm}$ \\
Tower thickness & $t_{\text {tower }}$ & $3 \mathrm{~mm}$ \\
\hline
\end{tabular}




\section{Experimental setup}

The experimental campaigns were carried out at DHI in a large $30 \mathrm{~m} \times 20 \mathrm{~m}$ basin with a water depth of $3 \mathrm{~m}$. Figure 2 shows a top view of the basin, which also illustrates the experimental setup. For consistency the setup was chosen to follow the setup of previous test campaigns ([14],[21]). The wave basin consists of 60 individual wave paddles, (a), installed on the front side of the basin which enable creation of unidirectional waves, misaligned waves and directionally spread waves. In the opposite end of the wave paddles a passive parabolic wave absorber, (c), is placed which minimizes the reflection of the waves. Furthermore a foam is placed along the sides of the basin, in order to reduce the transversal reflection of the waves. The floater, (g), was installed 4 metres from the wave paddles.

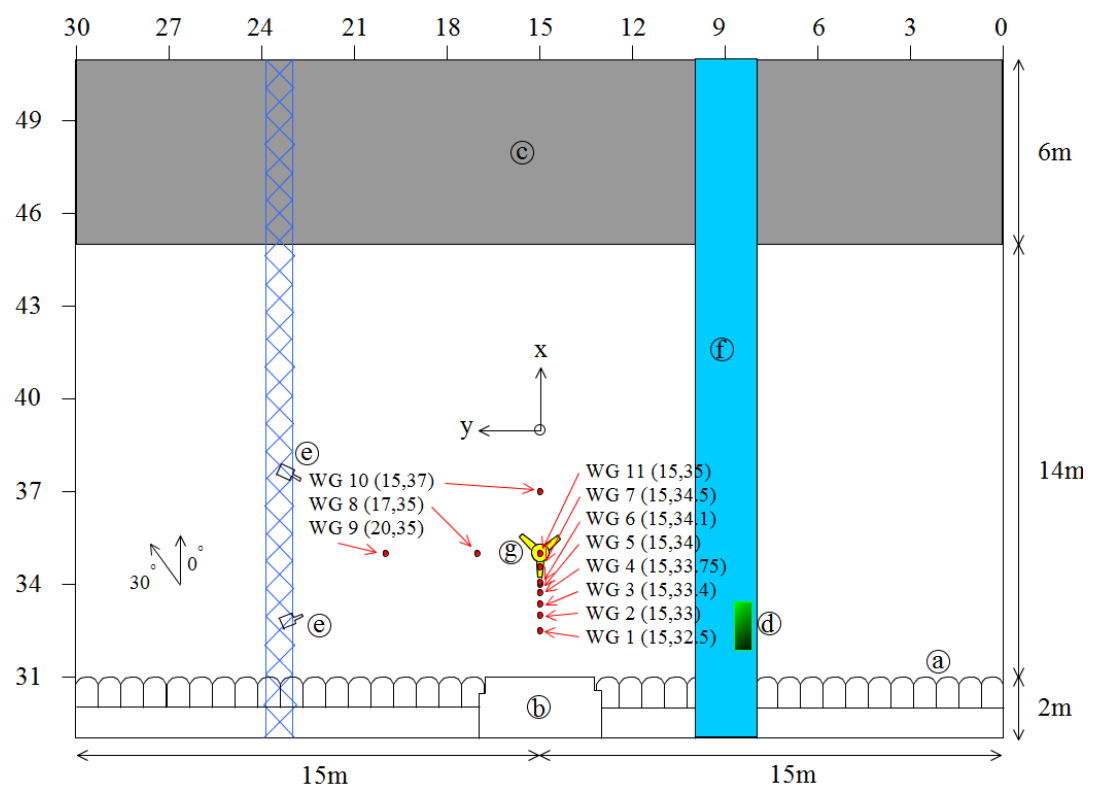

Figure 2: Top view of the wave basin and the experimental setup.

An open jet wind generator, (b), with an outlet area of $4 \mathrm{~m} \times 4 \mathrm{~m}$ was placed on the front side above the wave makers. It consists of six identical units with a fan in each that blows air laterally into a chamber, then guide vanes turns the flow $90^{\circ}$ into the main wave direction. More details on the wind generator design can be found in [14],[21].

Multiple sensors were installed on the wind turbine and all the signals were captured by a data acquisition device, (d), which was situated on the control bridge, $(\uparrow$, from where the experiments were controlled and monitored. Wave gauges (WG) were placed in the water to measure the wave elevation at eleven different locations in the basin, as shown in Figure 2. The six degrees of freedom 
floater motion was measured with a motion tracking system, Qualisys, which is a setup consisting of two cameras, (e), and tracking markers rigidly mounted at the tower bottom point. The inline and lateral shear force were measured using a shear force gauge installed between the nacelle and the tower top. In addition the inline and transverse acceleration in the nacelle were logged with two one degree of freedom accelerometers. The torque of the shaft servo motor governing the rotational speed was logged, together with the rotational speed of the shaft and the collective blade pitch.

Lastly a foundation to anchor the mooring lines was fixed on the basin bottom by the use of concrete blocks and lead bars which do not affect the wave motions during the experiments since the deep-water waves do not reach the basin bottom. Force gauges were installed at the fairlead connection to measure the mooring line tensions.

An overview of the sensors used in the test campaign is provided in Figure 3. More information about the calibration process as well as logging system and hardware setup can be found in [20].

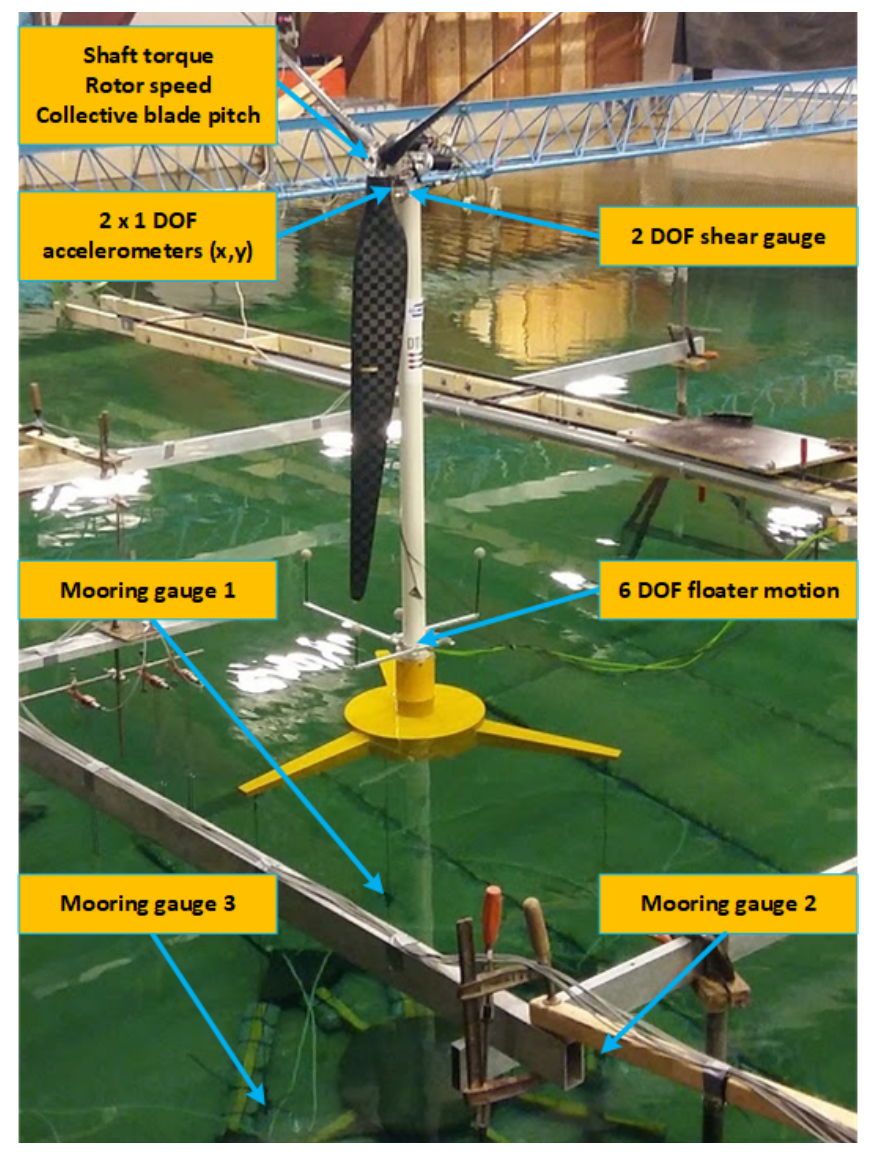

Figure 3: The floating wind turbine instrumentation. DOF: degree of freedom 
All the signals, except those of the wind turbine motors, were analogue signals that were fed into a data acquisition system and logged with a frequency of $160 \mathrm{~Hz}$. The signals coming from the two servo motors were digital signals and logged/controlled at $50 \mathrm{~Hz}$.

Four different environmental conditions (ECs) were considered for the experimental studies: one for below rated wind speed, one for around rated wind speed, one for above the rated wind speed, and one for extreme wind condition. The selected conditions are shown in Table 3 and were a subset of the full environmental conditions introduced by [21]. However, due to a limitation on the maximum rotational speed of the wind generator fans, a maximum mean wind speed of $2.2 \mathrm{~m} / \mathrm{s}$ at the turbine position could be achieved. Thus the scaled wind speed for EC6 and EC8 in Table 3 was reduced to $2.2 \mathrm{~m} / \mathrm{s}$.

Table 3: Table of target Environmental conditions (EC), taken from [21]. *: A wind speed of $2.2 \mathrm{~m} / \mathrm{s}$ was used for sea state $6 \& 8$ due to wind generator limitations.

\begin{tabular}{ll|cccc}
\hline \multicolumn{2}{l}{ Environmental condition } & EC3 & EC5 & EC6 & EC8 \\
\hline \multirow{2}{*}{$H_{s}[\mathrm{~m}]$} & Full scale & 3.30 & 4.16 & 6.18 & 10.0 \\
& Model scale & 0.055 & 0.069 & 0.103 & 0.167 \\
\hline \multirow{2}{*}{$T_{p}[\mathrm{~s}]$} & Full scale & 6.50 & 7.30 & 8.90 & 12.20 \\
& Model scale & 0.84 & 0.94 & 1.15 & 1.58 \\
\hline \multirow{2}{*}{$\bar{U}_{h u b}[\mathrm{~m} / \mathrm{s}]$} & Full scale & 8.5 & 11.4 & 18.0 & 33 \\
& Model scale & 1.1 & 1.5 & $2.3^{*}$ & $4.3^{*}$ \\
\hline \multicolumn{7}{c}{}
\end{tabular}

\section{Control}

The implementation of control systems to the experimental model required the development of an interface between the two servo motors on the model turbine and the dynamic-link library (DLL) of the controller itself. The control implementation is a further development from the one utilized in [14]. The interface consisted of (1) a PC, hosting the user-interface which allowed for real time interaction with the controller, i.e. shutdown and logging data, (2) a National Instruments (NI) MyRIO connected to the two servo motors, running the controller code in real-time, and (3) two NI DAQs were used to simultaneously log signals from the equipment shown in Figure 3. The latter allowed for synchronisation of the motion data with the operational parameters of the controller.

The implemented controller resembled the Basic DTU Wind Energy controller [18], although it only included the option of start-up and shutdowns along with control in the partial and full load region. Detailed mathematical formulations about the controller can be found in [18]. In addition, it should be noted that the main point of the tuning process in this paper was to match the scaled thrust curve rather than to match the scaled torque since the dynamic behaviors of the scaled floating wind turbine with different controllers were the most interesting phenomena to understand in this paper. 
The objective for control in the partial load region is to maximize the generated power meaning that the turbine should operate at maximum value of the power coefficient, $C_{p}$. This is achieved by keeping the blade pitch setting and Tip Speed Ratio, TSR $=R \omega / v$ where $R$ is the blade radius, $\omega$ is the rotational speed, and $v$ is the wind speed. The partial controller thus adjusts the generator torque based on the rotational speed. This type of controller is well known and is called a $K-\omega$ controller where $0.0089\left(\mathrm{Nm} /(\mathrm{rad} / \mathrm{s})^{2}\right)$ of the optimum $K$ value is used both for on- and offshore controller. The partial controller flowchart can be found in Figure $4 a$.

The full load controller on the other hand has the objective to keep the rotational speed and generated power at their respective rated values. This is done by adjusting the collective pitch angle of the blades in response to errors in rotational speed based on a PI controller. The gains of the PI controller are scheduled based on changes in the pitch angle to compensate for variations in the operating point of the wind turbine. The flowchart of full load controller is shown in Figure 4b. Full details of the controller is given in [18].

Two different closed-loop controllers were tested for the scaled floating wind turbine. The first controller was for a typical onshore turbine. It was tuned by pole-placement technique. The second one is for a floating wind turbine. The onshore controller is tuned such that control actions do not excite the natural frequencies of the structure where the integral and proportional gains were $0.1(\mathrm{Nm} / \mathrm{rad})$ and $0.28(\mathrm{Nm} /(\mathrm{rad} / \mathrm{s}))$, respectively. For the floating wind turbine controller, the task is more challenging than the onshore wind turbine as the frequencies of the moving platform must be taken into account. The natural frequencies of the platform motion are very low therefore the tuning of the controller was adjusted in order to avoid instability where the integral and proportional gains were $0.02(\mathrm{Nm} / \mathrm{rad})$ and $0.07(\mathrm{Nm} /(\mathrm{rad} / \mathrm{s}))$, respectively.

Instability for the platform motion, often referred to as 'negative damping' [23], can occur when the blade pitch controller is acting at one of the low frequency platform modes. As the platform moves forward, the rotor experiences a stronger apparent wind speed and increases the blade pitch. This reduces thrust and the forward motion is slightly amplified. A similar interaction occurs at the backward movement thus leading to resonant motion.

An important aspect of offshore control design is to ensure that the excitation frequencies do not coincide with the natural frequencies of the structure. Moreover, the wind turbine is also effected by the 1P and 3P frequencies from the rotating blades. All these factors have to be considered in the design phase of the offshore controller. If, however, the excitation forces coincide with the natural frequencies of the structure, resonance may occur with consequent increase in fatigue loads. The overview of frequencies is illustrated in Figure 5 where an operational range of $\Omega=(53.02,74.37) \mathrm{rpm}$, a wave climate with frequencies ranging between $f_{\text {wave }}=(0.63,1.19) \mathrm{Hz}$ and the natural frequencies determined in section 5.4 are shown. 


\section{Partial Load Controller}

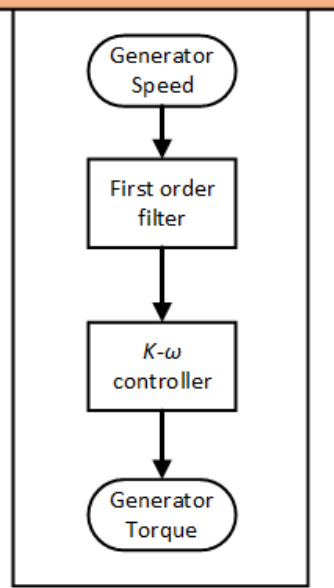

(a) partial load controller

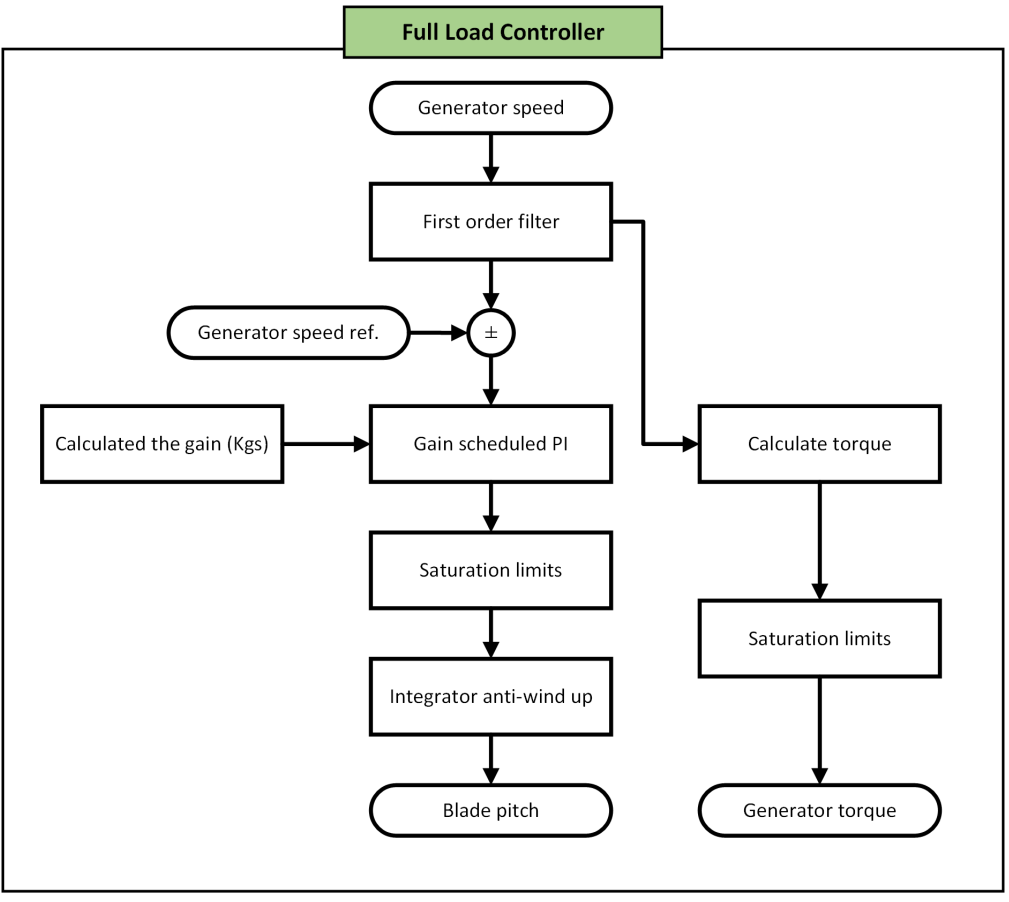

(b) full load controller

Figure 4: Flowchart of the controller 


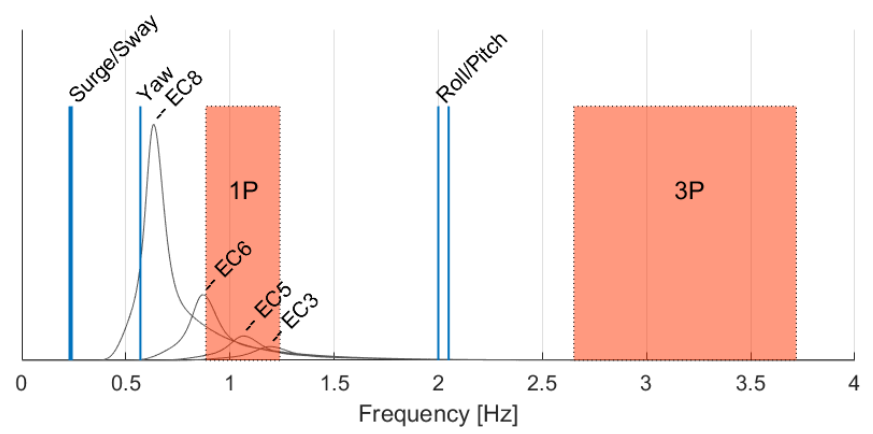

Figure 5: Natural frequencies of the six degrees of freedom and the excitation frequencies from the rotational speed of the rotor and the waves.

\section{Climate validation}

In this section we investigate to what extent the environmental conditions produced by the experimental setups such as wind generator, wave maker, wind turbine etc. resemble the target climates.

\subsection{Wind climate}

Prior to the production tests, the wind field generated from the six individual units was measured by sweeping four single component hot-wire air velocity probes across the frontal plane at the turbine equilibrium position, in which the rotor plane is a subset. A single probe was mounted on the wind generator to be present throughout the production tests.

A wooden frame with a steel rail on top was constructed, which would allow a cart with a pole to sweep across the wind field. The probes were then mounted on the pole and the cart was moved between five different positions across the plane for three different vertical positions of the probes. The wind speed was sampled for approximately $120 \mathrm{~s}$ in each position, corresponding to 15 minutes in full scale time.

The measurements were used for calibrating the commanded rotational speed of the wind generators and obtaining a correlation between the wind speed measured by the probe at the wind generator and the wind speed measured at the wind turbine position.

The sweep measurements were used to estimate the mean wind speed $V$ and turbulence intensity $T I$ in the rotor plane. The results for the three wind speeds of $V=(1.10,1.47,2.20) \mathrm{m} / \mathrm{s}$ are shown in Figure 6. The rotor area is marked by a black circle and as it is evident that the measurements do not cover the entire rotor area, due to the cart having a certain height above the water, which is approximately $11 \%$ of the total rotor area. This means that in the azimuthal range $135-225 \mathrm{deg}$ the outer region of the blades will experience a drop in wind speed and an increased turbulence intensity. The results show that the wind field is relatively uniform and has low turbulence for the majority 

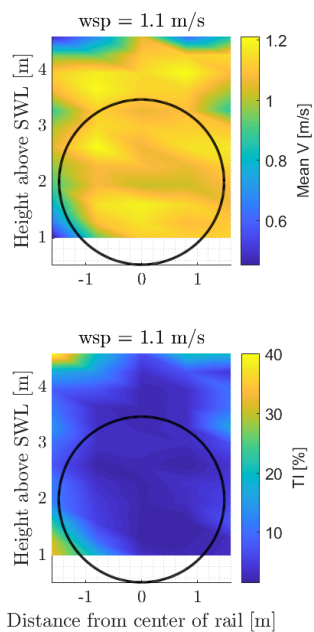

of the rotor area, with an overall mean turbulence intensity across wind speeds of about $3.5 \%$. This means that the performance of the wind generators is overall satisfying. However it can be observed that the wind field in the lower left corner of the swept area is exposed to high turbulence and a significant low wind speed. This is likely due to a slight nonuniformity of the guiding vanes in the lower left wind generator, as stated in [16], resulting in the flow being directed to the center of the domain instead of making the flow uniform.
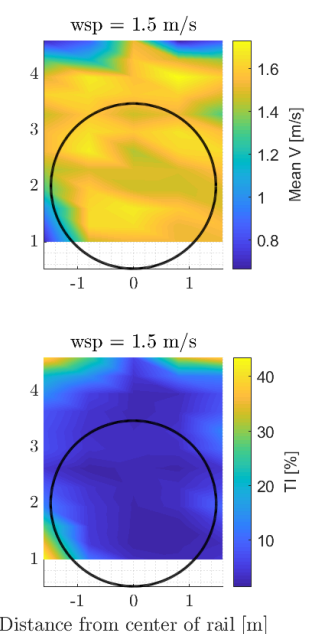
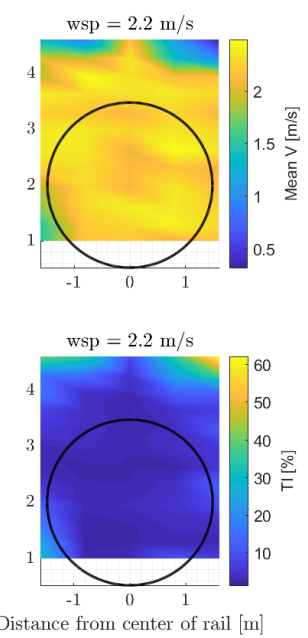

Figure 6: Wind velocity fields and turbulence intensity field based on point measurements of wind speed averaged over 60 seconds.

\subsection{Wave climate}

Prior to mounting the floating wind turbine in the wave basin the wave fields were measured for the most severe sea state, namely EC8. A comparison was done based on wave gauge 8 and 9 shown in Figure 2 and the measured wave elevation and period have been compared to the target Pierson-Moskowitz spectrum. Figure 7 shows the measured spectrum of 5 realisations of each sea state compared with the target spectrum. A moving average filter was applied to the data. It is observed that the raw power spectral density (PSD) spectra compares well with the shape of the corresponding target spectrum. A comparison of $H_{s}$ and $T_{p}$ is shown in Table 4. EC8 shows a large difference in $T_{p}$ of $17.7 \%$ between target and measured. However, Figure 7 reveals a rather flat crest for the measured power-spectra, which introduce uncertainty in the determination of the measured $T_{p}$ for EC8. In general, the match for the shape of the spectrum is good. The wave generation builds on linear wave theory and a clean Pierson Moskowitz spectrum. The observed local peaks other than the peak spectra period might be related to generation of second-order effects from the paddles of the wave maker. Since the theoretical spectra are based on linear theory it does not capture second-order effects. 
Table 4: Validation of irregular waves, $H$ wave height and $T$ wave period

\begin{tabular}{cc|cccc} 
& & EC3 & EC5 & EC6 & EC8 \\
\hline \multirow{3}{*}{$H_{s}$} & Target & 0.055 & 0.069 & 0.103 & 0.167 \\
& Measured & 0.057 & 0.072 & 0.102 & 0.165 \\
& Difference [\%] & 3.6 & 4.3 & 0.97 & 1.2 \\
\hline \multirow{2}{*}{$T_{p}$} & Target & 0.84 & 0.94 & 1.15 & 1.58 \\
& Measured & 0.83 & 0.90 & 1.12 & 1.30 \\
& Difference [\%] & 1.2 & 4.2 & 2.6 & 17.7 \\
\hline
\end{tabular}

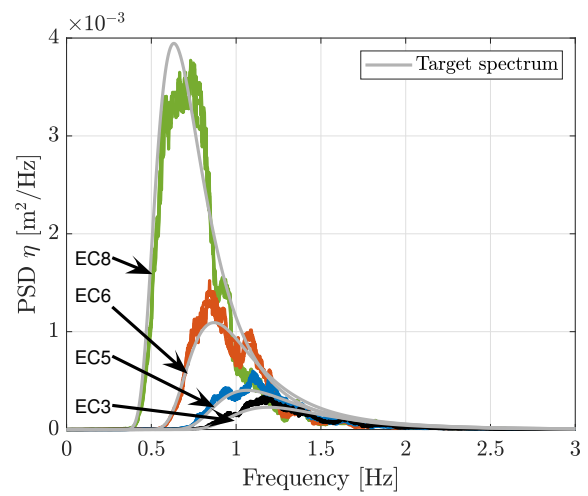

Figure 7: Validation of irregular waves for the four environmental conditions (EC).

\subsection{Rotor thrust}

In the downscaled test of offshore platforms, priority is traditionally given to the preservation of the Froude number, Fr. This means that the Reynolds number, $R e$, is not preserved, which represents a challenge when aerodynamics are involved. In our case, this means that for a given mean wind speed, $V$, a direct geometrically downscaled rotor will generally produce a different mean thrust force, $T$, than the reference DTU10MW wind turbine for the same rotor speed and blade pitch angle. The aerodynamic thrust is the most important aerodynamic element in the overall dynamics of a floating wind turbine, therefore it is desired to match the scaled thrust of the reference wind turbine for each wind speed. In the experimental setup, the rotor speed was always set to the downscaled reference value, and the match of the reference steady thrust curve was carried out by modifying the blade pitch settings for each wind speed until the mean thrust was equal to the target, see Figure 8. Since the rotor was designed with special low $R e$ airfoils and a $75 \%$ increased chord, the steady thrust match was achieved with only minor adjustment of the blade pitch angle. 

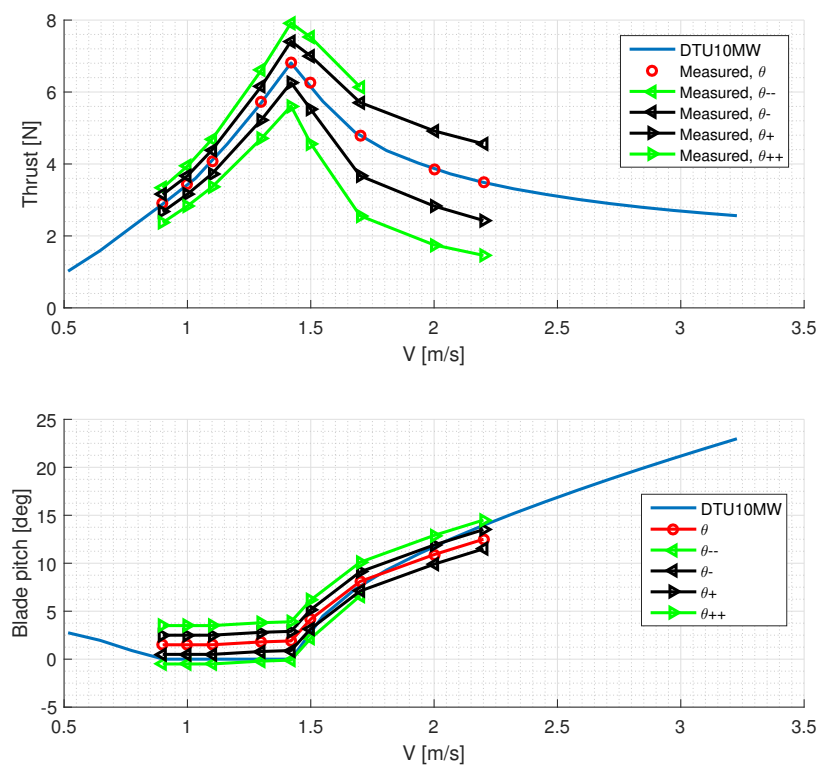

Figure 8: Rotor thrust tests for the wind turbine. Note that $\theta_{ \pm}$corresponds to a 1 or 2 deg deviation from the desired pitch angle setting.

In Figure 8 the initial blade pitch setting $\theta$ (bottom, red line) necessary to obtain the target thrust (blue line) is shown for the model and used as input to the controllers. In order to understand the sensitivity of the change of thrust over change of blade pitch, a sensitivity analysis was conducted for each determined blade pitch setting (red line) and the thrust curves for the sensitivity analysis correspond to deviations of \pm 1 and 2 deg from $\theta$ (top, black and green lines: -1 and -2 deg and bottom, black and green lines: +1 and +2 $\mathrm{deg})$. However, for wind speed $1.7 \mathrm{~m} / \mathrm{s}$, the case where the blade pitch is $\theta-2$ produced aerodynamic torque beyond the limits of the wind turbine motor. Therefore, the sensitivity analysis for wind speeds 2.0 and $2.2 \mathrm{~m} / \mathrm{s}$ was only carried out with for $\theta-1, \theta+1$ and $\theta+2 \mathrm{deg}$.

\subsection{System free decay tests}

Free decay tests of the entire floating wind turbine system including all structural properties were carried out by imposing an initial displacement to the structure in each of the degrees of freedom. By then releasing the structure the system characteristics can be determined, such as natural frequencies and the system damping. A line was attached to the structure, in order to impose a displacement in each of the degrees of freedom. In surge and sway, the line was attached to the floater at the waterline level. In roll and pitch, the line was attached some distance along the wind turbine tower. In yaw, the line was attached to the fairlead on the front spoke. Due to the high stiffness of 
the system in heave and the risk of slack tendons, it was not possible to get out satisfactory results for heave. The heave frequency is thus marked with brackets in Table 5 and the corresponding damping ratio could not be estimated.

The measured natural frequencies and damping ratio are listed in Table 5, which are obtained based on the power spectra of the decay test. For each degree of freedom, three free decay tests were done in succession. Thus the values in Table 5 represent the average across these three decay tests. Initial displacements of varying amplitudes were imposed in an attempt to capture both linear and nonlinear behaviour. However, due to the limitations of the method in applying the initial displacement for each degree of freedom as well as the expected nature of the system, it was not possible to completely isolate an initial displacement in the desired degree of freedom without inducing an initial displacement in other degrees of freedom. This was particularly seen for surge and pitch, and sway and roll, due to the strong couplings between these degrees of freedom.

Table 5: Measured natural frequencies and damping ratios from experiments.

\begin{tabular}{lcccccc} 
& Surge & Sway & Heave & Roll & Pitch & Yaw \\
\hline ExPERIMENTS & & & & & & \\
Frequency [Hz] & 0.24 & 0.23 & $(9.83)$ & 2.05 & 2.00 & 0.57 \\
Damping ratio $\zeta[$ [ & 0.08 & 0.08 & - & 0.06 & 0.06 & 0.09 \\
\hline
\end{tabular}

\subsection{Environmental conditions and turbine operational parameters}

Based on the obtained validation results a complete table describing the environmental conditions (EC) and turbine operational parameters are provided in Table 6. It shows the wave height, $H_{s}$, period, $T_{s}$, the wind speed at hub height, $V_{h u b}$, and the corresponding operational conditions; rotor speed, $\Omega$, and blade pitch, $\theta_{p}$, for the open loop controller (also noted "fixed"). EC8 is meant to represent storm conditions with a parked turbine. However it was decided to have the turbine active in EC8, as the wind speed could not exceed $2.2 \mathrm{~m} / \mathrm{s}$ due to the limitations of the wind generators.

Table 6: Environmental conditions and turbine operational parameters for the experiments. A wind speed of $2.2 \mathrm{~m} / \mathrm{s}$ was used for sea state $6 \& 8$ due to wind generator limitations.

\begin{tabular}{c|ccc|cc} 
& \multicolumn{3}{|c|}{ Environmental conditions } & \multicolumn{2}{c}{ Turbine operational parameters } \\
\hline & $H_{s}[\mathrm{~m}]$ & $T_{s}[\mathrm{~s}]$ & $V_{\text {hub }}[\mathrm{m} / \mathrm{s}]$ & $\theta_{p}[\mathrm{deg}]$ & $\Omega[\mathrm{rpm}]$ \\
\hline EC3 & 0.055 & 0.84 & 1.1 & 1.50 & 53.02 \\
EC5 & 0.069 & 0.94 & 1.5 & 4.17 & 72.11 \\
EC6 & 0.103 & 1.15 & 2.2 & 12.50 & 74.37 \\
EC8 & 0.167 & 1.58 & 2.2 & 12.50 & 74.37 \\
\hline
\end{tabular}




\section{Experimental Results}

\subsection{Effect of wind and wave misalignment}

The irregular sea states consist of several wave groups with different heights and lengths. Hence they are best suited to represent real sea states. However, due to the random nature of irregular waves, the comparison of responses in time series becomes impractical. Therefore the exceedance probability $P$ is introduced.

For each signal and for each environmental state, the peaks were identified and stored based on a wave elevation zero down-crossing [24]. The time series of the incident wave elevation is divided into individual waves, where each wave is defined between two zero down-crossings of the free surface elevation. The maximum values of the specific signal are then determined within each time range defined by the individual waves and stored. The peaks $X$ are sorted from minimum to maximum and assigned with an index $i$ to compute the exceedance probability based on the index and the total number of peaks $N$. This approach ensures that only one independent response peak per wave is registered [21] and the exceedance probability $P$ can be defined as:

$$
P=p\left(X \geq x_{i}\right)=1-\frac{i}{N+1}
$$

All the misaligned irregular wave tests were conducted with a wave heading of $\beta=30^{\circ}$ as defined in Figure 9. When dealing with misaligned waves, the response is typically projected into the wave coordinate system, see Figure 9. This allows for a more appropriate comparison of the effect of misalignment on the different degrees of freedom, hence the surge, sway, roll, and pitch $\left(\xi_{1}, \xi_{2}, \xi_{4}, \xi_{5}\right)$ in cases with misalignment were projected into the direction of the wave propagation, while heave and yaw $\left(\xi_{3}\right.$ and $\left.\xi_{6}\right)$ remained unchanged. It should also be noted that the nacelle accelerations were also projected into the wave coordinate system.

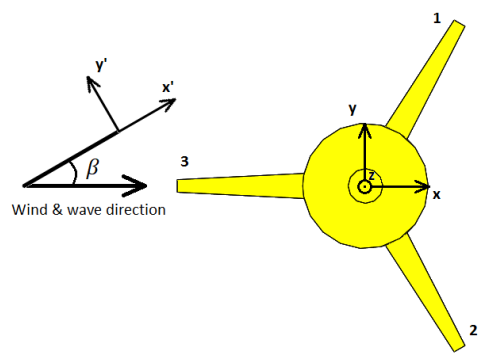

Figure 9: Wave coordinate system and global floater coordinate system.

Since the impact from the aerodynamic force is largest at rated conditions (EC5), it is chosen for the misalignment analysis. Furthermore the closedloop controller tuned for the offshore floating configuration was used for the 
cases with wind. The response in the six degrees of freedom for tests with and without wind had their corresponding mean subtracted from the signals in order to highlight the differences in the dynamics.

This means that four cases will be presented in each figure; aligned and misaligned waves with and without wind. Furthermore the power density spectra of the responses will be presented together with the exceedance probability curves.

The effect of misalignment and wind on surge motion and nacelle fore-aft and side-side accelerations for EC5 are shown in Figure 10. The surge motion in aligned waves and without wind (blue) shows as expected the largest response and the effect of the aerodynamic damping can be seen on the exceedance probability plot, as the response with wind included (red), is smaller. However, the damping effect is minor for the misaligned waves case (yellow and purple), as only a component of the wind will affect the surge. Thus the aerodynamic damping is strongest on the surge motion for unidirectional conditions. If the signals did not have their mean value subtracted, a permanent offset for the wind and wave misaligned case would be expected, since the wind will induce a component in the negative $y^{\prime}$-direction, see Figure 9. 

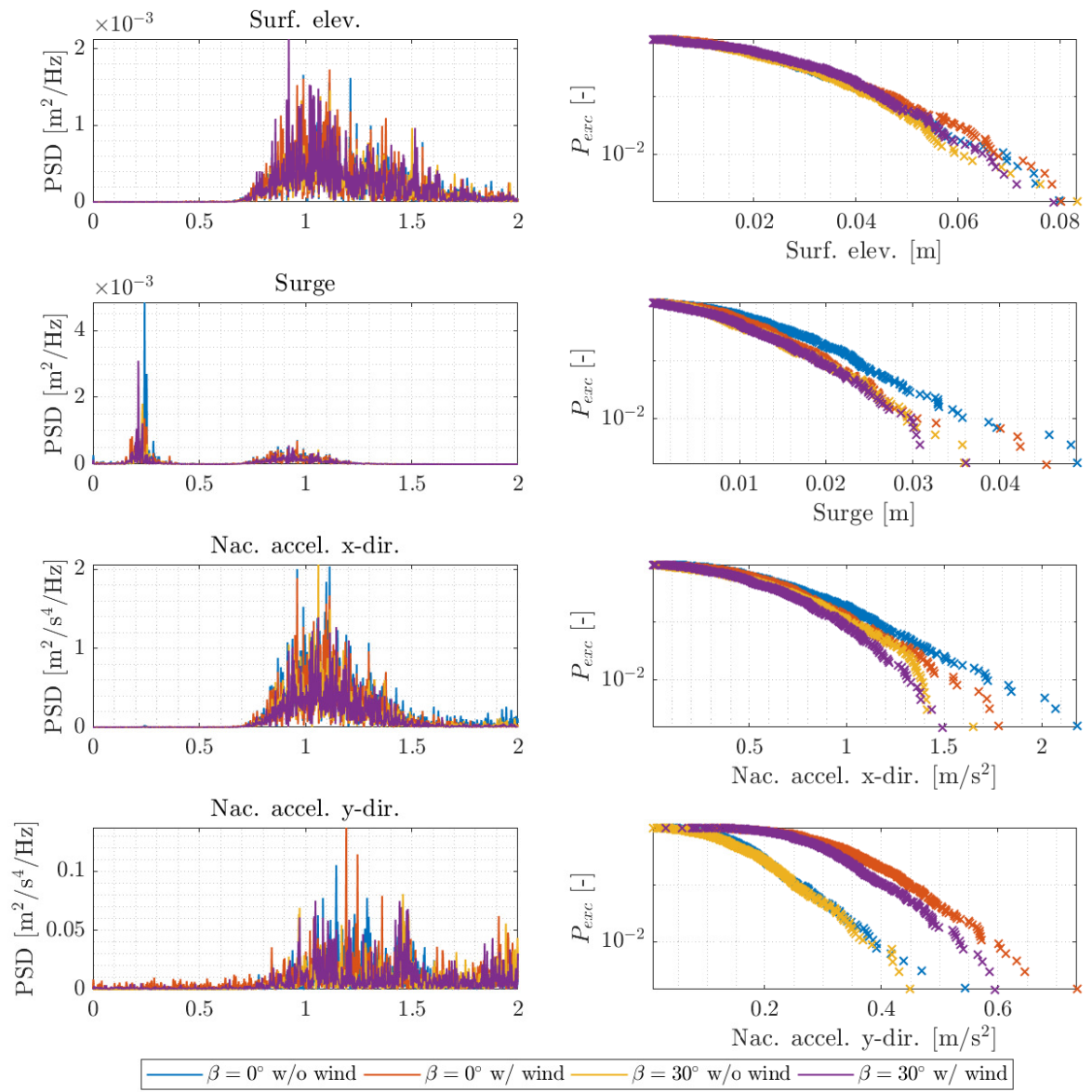

Figure 10: The comparison of floater surge response and nacelle accelerations in irregular waves with wave heading $\beta=0^{\circ}$ and $\beta=30^{\circ}$ with and without wind for EC5. Mean values have been subtracted and the signals have been projected into the direction of the wave propagation. The $x, y$-directions refer to fore-aft and side-side accelerations in the wave coordinate system, see Figure 9.

The same can be observed for the nacelle accelerations exceedance probability plots in the $x$-direction, which were also transformed into the wave coordinate system. Here the cases without wind also lie above the cases with wind. It can also observed that introducing wind to the system will increase the out-of-plane acceleration ( $y$-direction).

Figure 11 presents the normalised tension in the three mooring lines at rated wind speed. It can be observed that, for the tension in mooring line 3 (see Figure 9 ), the wind-induced mean moment adds a permanent positive increase in the mean value for both aligned and misaligned conditions. The opposite picture is present for mooring line 1 and 2 .

Further, the tension in mooring line 1 appears to be unaffected by misaligned 

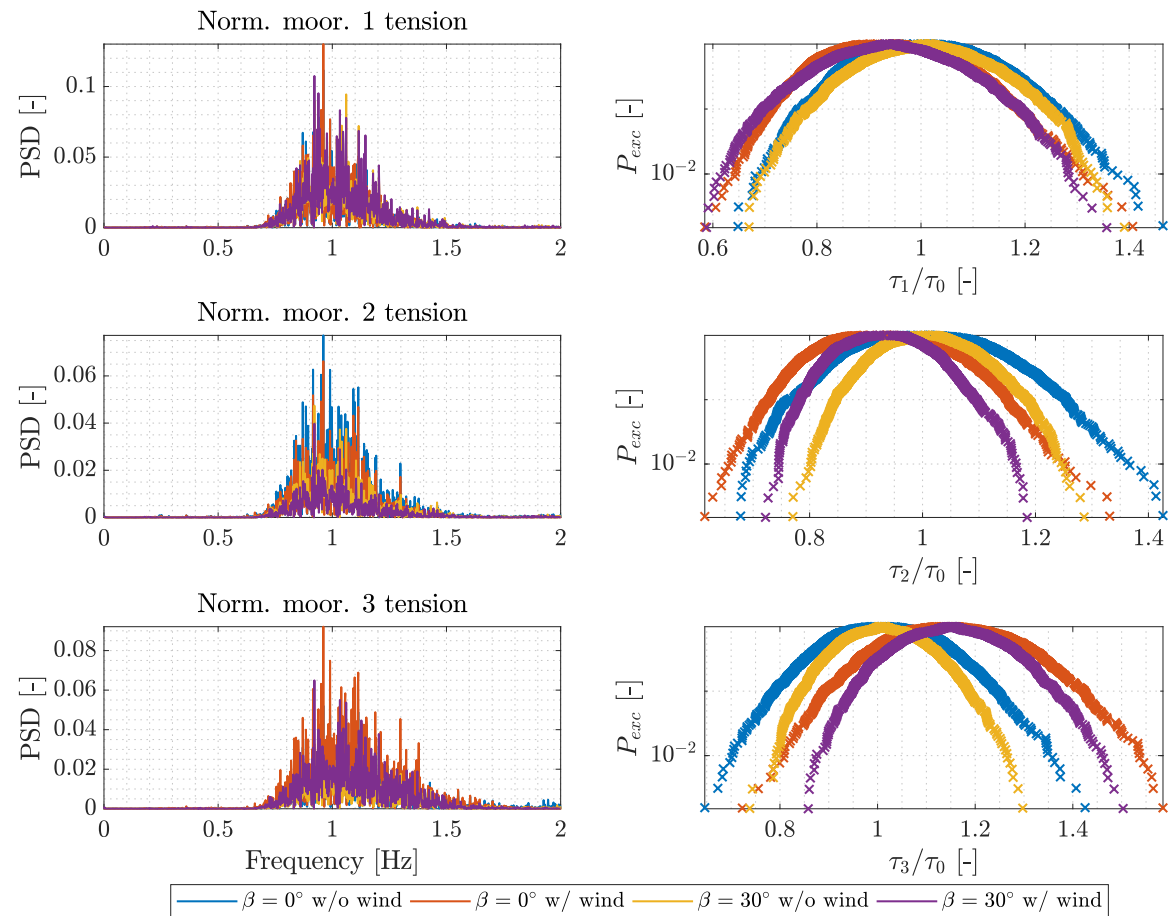

Figure 11: Normalised mooring line tensions in irregular waves with wave heading $\beta=0^{\circ}$ and $\beta=30^{\circ}$ with and without wind for EC5. Mean values have not been subtracted, but the tensions are normalised with the equilibrium state $\tau_{0}$, thus the tensions in calm water and without wind. The labelling of $\tau_{i}$ refers to Figure 9.

waves or wind, which could be due to the wave direction in $x^{\prime}$ achieving only offset of $30^{\circ}$ offset with spoke number 1 . Furthermore the overall magnitude of the loads in the two other mooring lines decrease slightly when misaligned waves are applied.

\subsection{Controller performance}

\subsubsection{Regular waves}

The three controllers are compared with respect to their impact on the system response and they will in following be referred to as offshore, onshore and fixed which refer to the closed-loop controller tuned for offshore floating configuration, the closed-loop controller tuned for onshore and the open-loop controller with fixed rotational speed and fixed blade pitch, respectively. 

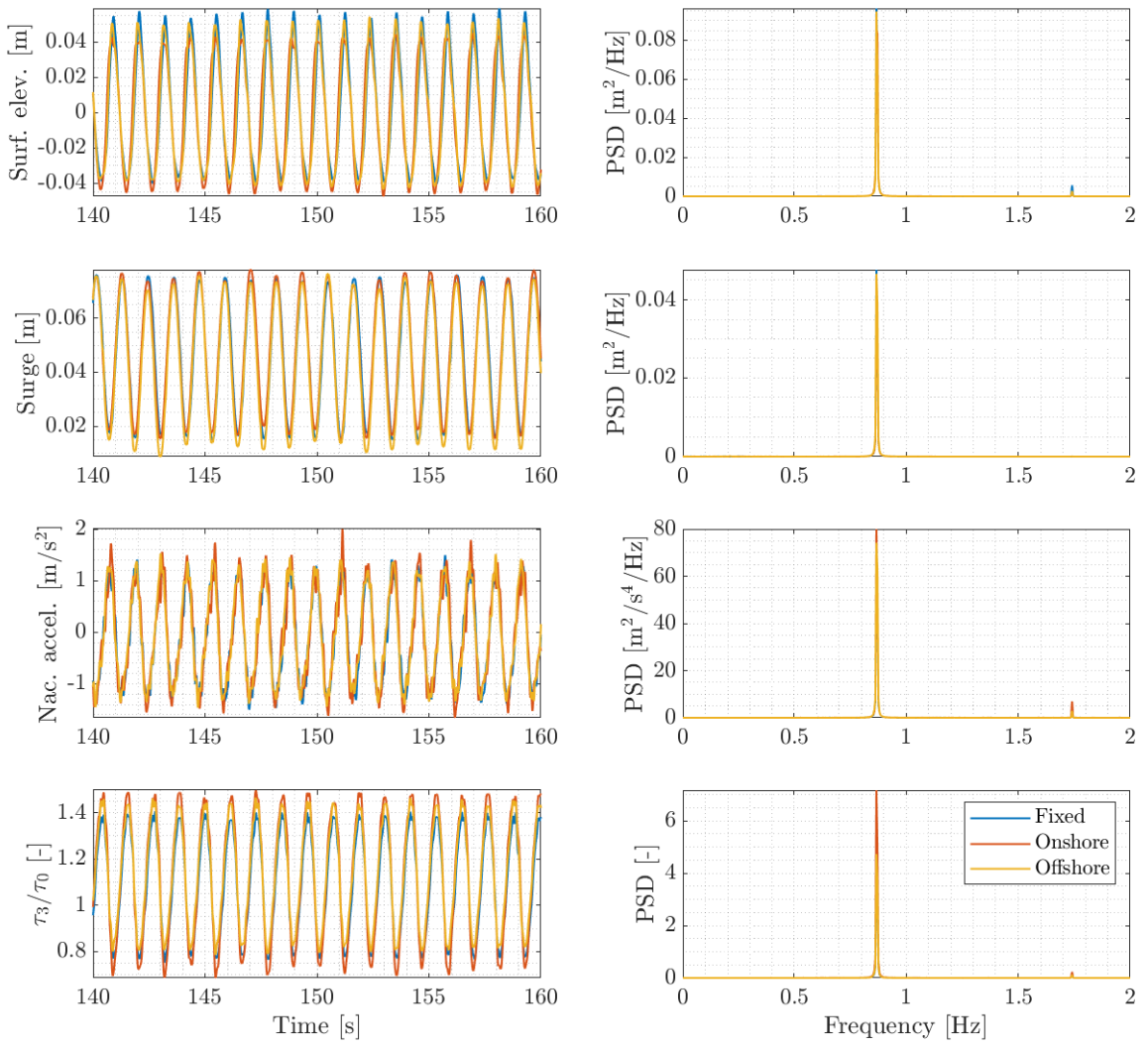

Figure 12: Surge, nacelle fore-aft acceleration and normalised front mooring line tension for regular waves in EC6 with different controllers.

In Figure 12 the surge motion, nacelle fore-aft acceleration and front mooring line tension are presented together with their corresponding power spectra for environmental conditions. The analysis is done for environmental conditions above rated wind speed conditions, in this case EC6, to better isolate the effects from the full-load controller. It is observed that the surge motion, nacelle foreaft acceleration and front mooring line tension are dominated by response at the wave frequency at $0.87 \mathrm{~Hz}$. Furthermore minor low-frequency response is visible for particularly the onshore controller in the time series, oscillating with the natural frequency of surge, $0.24 \mathrm{~Hz}$. However this contribution, compared to the wave excitation, is significantly lower, and thus not visible in the PSD plot. Only by observing the PSD in logarithmic scale, a minor contribution can be seen. The higher surge motion for the onshore controller compared to the offshore and open loop controller, will result in higher mooring line tensions. The front mooring line tension can be observed to be up to $3 \%$ higher for the onshore controller compared to the offshore controller and $6 \%$ higher than the open loop controller. It is observed that all three controllers achieve approximately the 
same nacelle accelerations and with dominating response at the wave frequency. However the onshore controller is also excited slightly at the second wave peak frequency, i.e. $T_{p} / 2$, and tend to have higher extreme values.

Figure 13 shows the operational data of the turbine, blade pitch and rotational speed with corresponding power spectra, for the same environmental conditions above rated wind speed (EC6). As expected, rapid and large-amplitude blade pitch response is seen for the onshore controller for rated conditions, whereas the offshore controller is more slow, thus much less aggressive. This emphasizes that the offshore controller is tuned to handle motion due to waves rather than control due to wind. The extreme blade pitching of the onshore controller also affects the rotational speed and causes higher magnitude of oscillations. Further it is seen, that the rotational speed of the fixed controller configuration is not constant. This is due to the servomotor on the shaft not being able to supply the needed torque to stay at the desired rotational speed value.
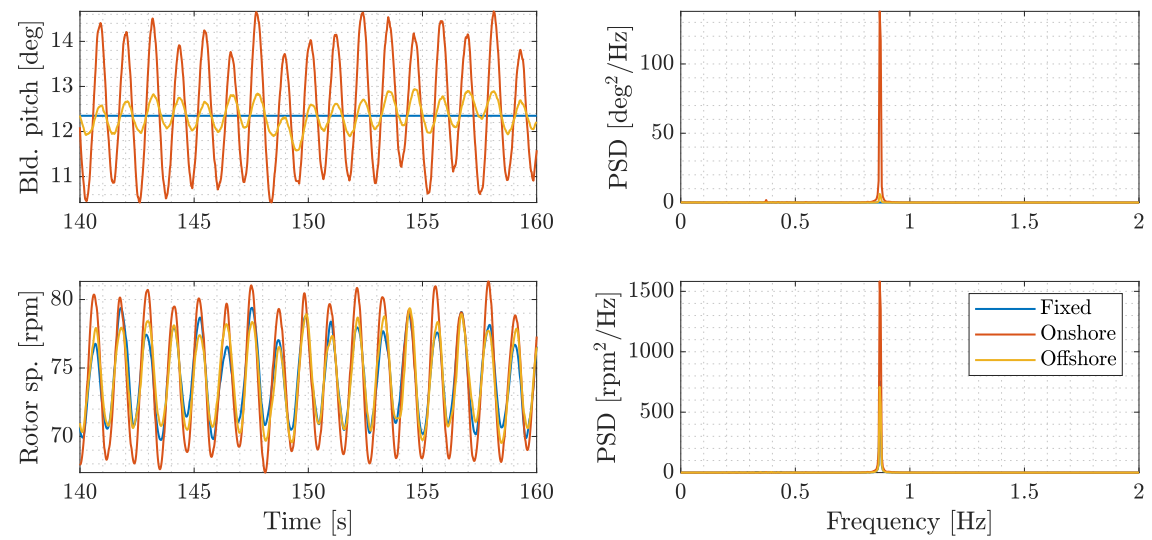

Figure 13: Turbine operational data (blade pitch and rotational speed) for regular waves in EC6 with different controllers.

In addition in Figure 14 the mean and standard deviation for the regular wave cases are presented with respect to surge motion, nacelle fore-aft acceleration and front mooring line tension. The reader should recall that the wind is the same for EC6 and EC8 due to limitations of the wind generators and only the waves are larger for EC8.

The mean surge response has a local maximum at rated wind speed (EC5) due to the trend of the thrust curve, but then as the environmental conditions become more severe (EC8), the mean is increased. This is due to the increased non-linear effects, which are more severe for larger wave amplitudes, imposing a mean drift force, a trend that can be seen in both the surge response and the mooring tensions. Similar tendencies are observed for the the tensions in the front mooring line. Furthermore it is observed that the standard deviation of the tensions for the onshore controller are increasing rapidly for higher environ- 
mental states compared to the two other controllers. This is due to the negative aerodynamic damping for this controller.

It can be observed that the means of the nacelle fore-aft acceleration are close to zero for all environmental states, which is to be expected. The slight offset from zero is due to the small wind-induced mean pitch moment that introduces a gravitational component. Since a horizontal gravity component will be captured by the accelerometer and the fact that the center of mass for the Rotor Nacelle Assembly (RNA) is located slightly upwind, there is an offset in the negative direction. Further the standard deviation shows, an increase with increasing sea state, but more rapidly for the onshore controller.

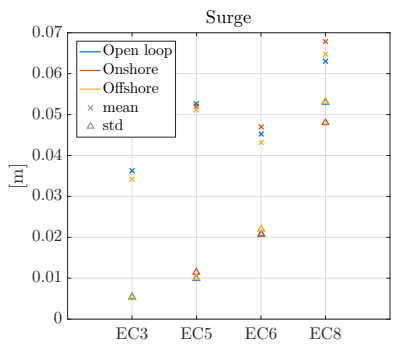

(a)

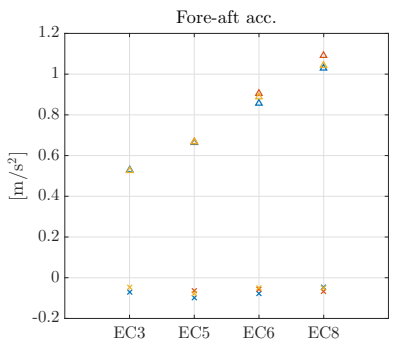

(b)

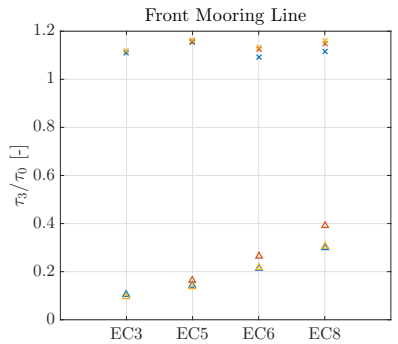

(c)

Figure 14: Mean and standard deviation for (a) Surge, (b) Nacelle fore-aft acceleration, (c) Normalized tension in the front mooring line

\subsubsection{Irregular waves}

The three different control systems are now analysed in aligned irregular waves. Comparison of the controllers will be carried out based on the response above rated conditions, EC6.

Figure 15 shows the influence of the three controllers on the surge motion, nacelle fore-aft acceleration and front mooring line tension (normalized). In general, the offshore controller performs best as it keeps the dynamic surge response and the front mooring line tension low. Overall the performance of the onshore controller results in larger surge response than the offshore controller, thus leading to larger front mooring line tensions. It is seen that the surge motion for the three controllers are dominated by a combination of excitations of the surge natural frequency and at the wave frequency range. The nacelle acceleration and front mooring line tension are on the other hand only dominated by the waves. 

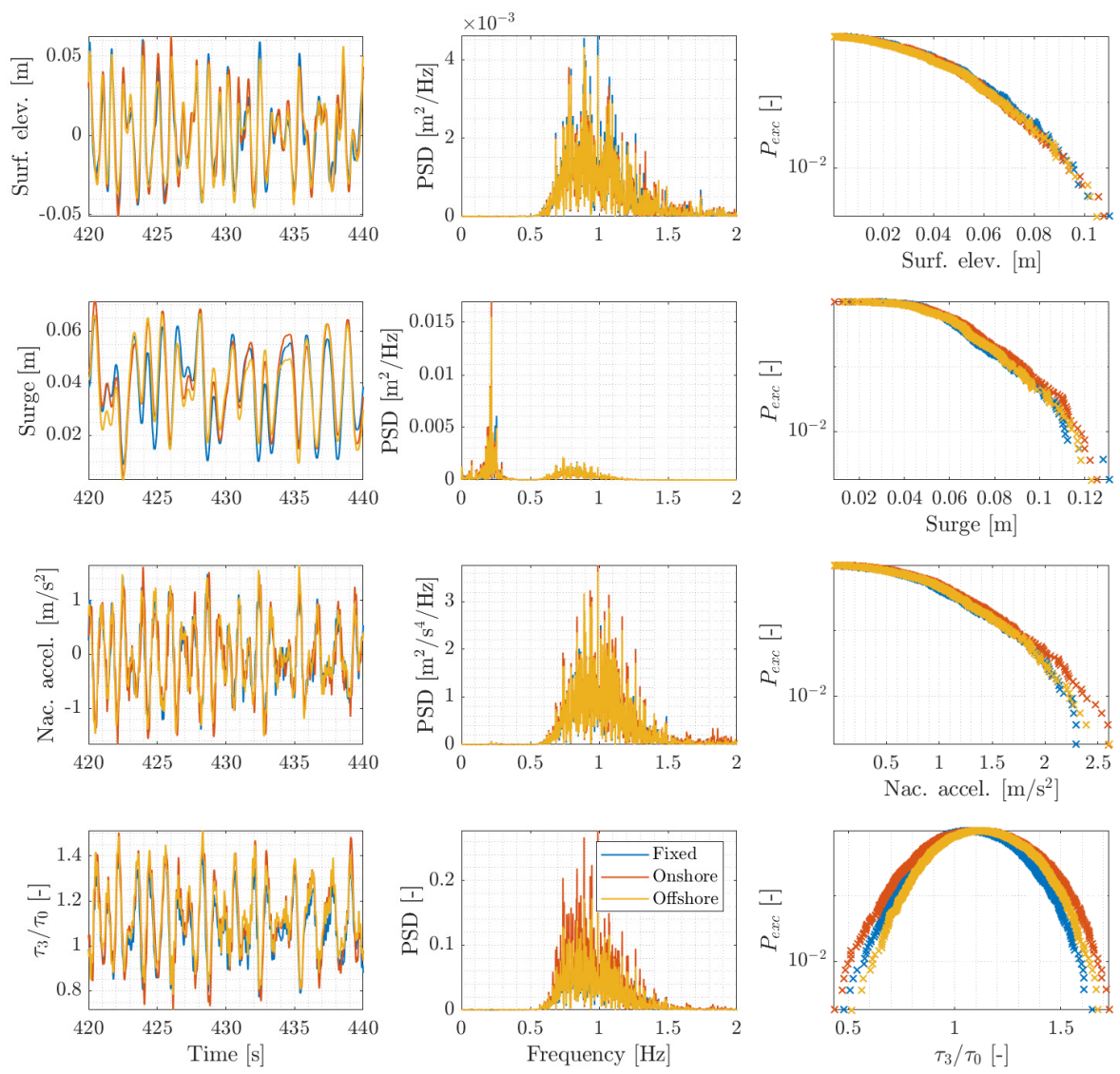

Figure 15: Surge response of the floater platform, nacelle fore-aft acceleration and normalised front mooring line tension in irregular waves with three different controllers for EC6.

Corresponding blade pitch and rotational speed are presented in Figure 16. Note that for the closed-loop fixed control, a specific blade pitch angle is kept constant at $12.50^{\circ}$, hence a constant vertical line is seen in the exceedance probability plot. The aggressiveness of the onshore controller can be seen easily, as it pitches the blades more than the offshore controller. Looking at $90 \%$ percentiles of the blade pitch angle, the offshore controller is $12.9^{\circ}$, whereas the onshore is at $14.6^{\circ}$. Further it is seen from the PSD that the blade pitch is dominated by the waves for the onshore controller, whereas excitations at the surge natural natural frequency dominates the offshore controller. The effect of the aggressive pitching of the blades for the onshore controller causes likewise the rotational speed to achieve the highest values of all the three controllers. From the PSD it is clear that the rotational speed of the onshore controller is purely dominated by the waves, whereas it is combination of the waves and excitations of the surge natural frequency for the two other controllers. 

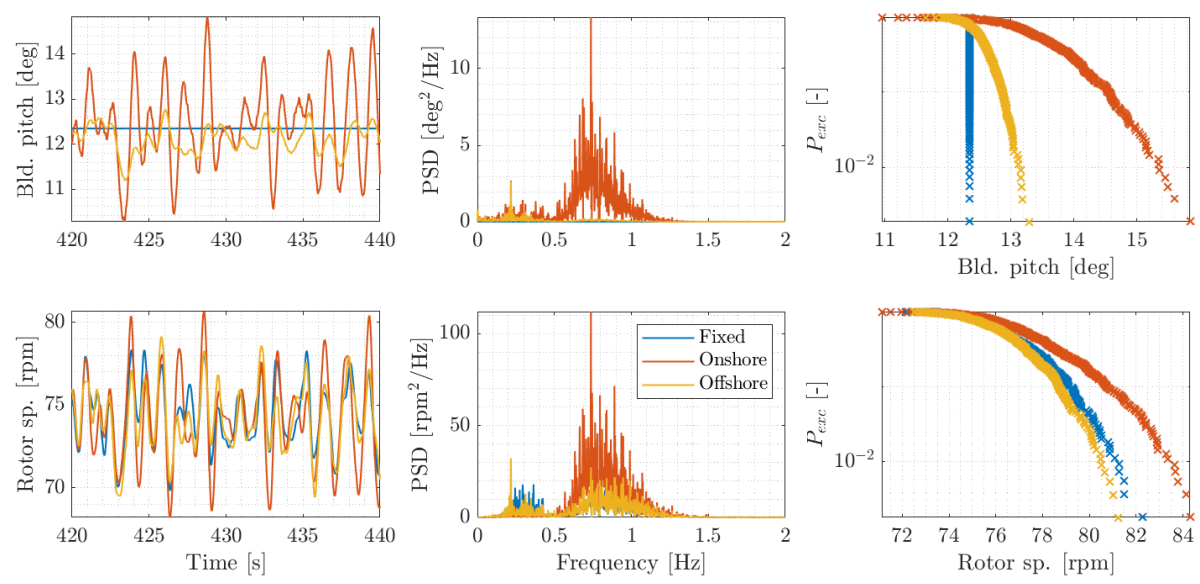

Figure 16: Turbine operational data (blade pitch and rotational speed) in irregular waves with three different controllers for EC6.

\subsubsection{Extreme focused wave groups}

Extreme wave epsisodes can be represented by the use of focused wave groups, which have similarities to the irregular wave type, as they are composed of a sum of individual waves over a range of frequencies. However, the focused wave groups have a chosen phase between the individual waves, resulting in a constructive merge at a single location $x_{0}$ and time $t_{0}$, namely the focus point. The surface elevation $\eta(x, t)$ for a group of focused waves can be described by:

$$
\eta(x, t)=\sum_{i=1}^{N} a_{i} \cos \left(\omega_{i}\left(t-t_{0}\right)-k_{i}\left(x-x_{0}\right)\right)
$$

where $a_{i}=S_{\eta}\left(f_{i}\right) \Delta f$ is the amplitude, $\omega_{i}=2 \pi f_{i}$ is the frequency and $k_{i}$ is the wave number of the individual waves. The maximum wave height, $H_{\max }$, for the focused wave signals is chosen as the 3 -hour value according to a Rayleigh distribution for linear waves, $H_{\max }=1.86 H_{s}[25]$.

The analysis presents the impact of a single large wave group on the structure giving insight into the extreme wave effects. The extreme response of the structure is investigated for the three controllers. In order to analyse the contributions from the wave frequency range and system natural frequencies, all measurements are presented with a time series in the left column and with corresponding power spectrum in the right column in Figure 17 and 18. Since only a single wave group is analysed, the probability of exceedance is not relevant here, and for this reason only the time series and corresponding PSD are shown. As in the previous control sections, the comparison of the controllers is carried out based on the response above rated conditions, EC6.

Figure 17 presents the wave elevation corresponding to the environmental state EC6 focused wave climate together with the surge motion, nacelle fore-aft acceleration and normalized front mooring tension. 

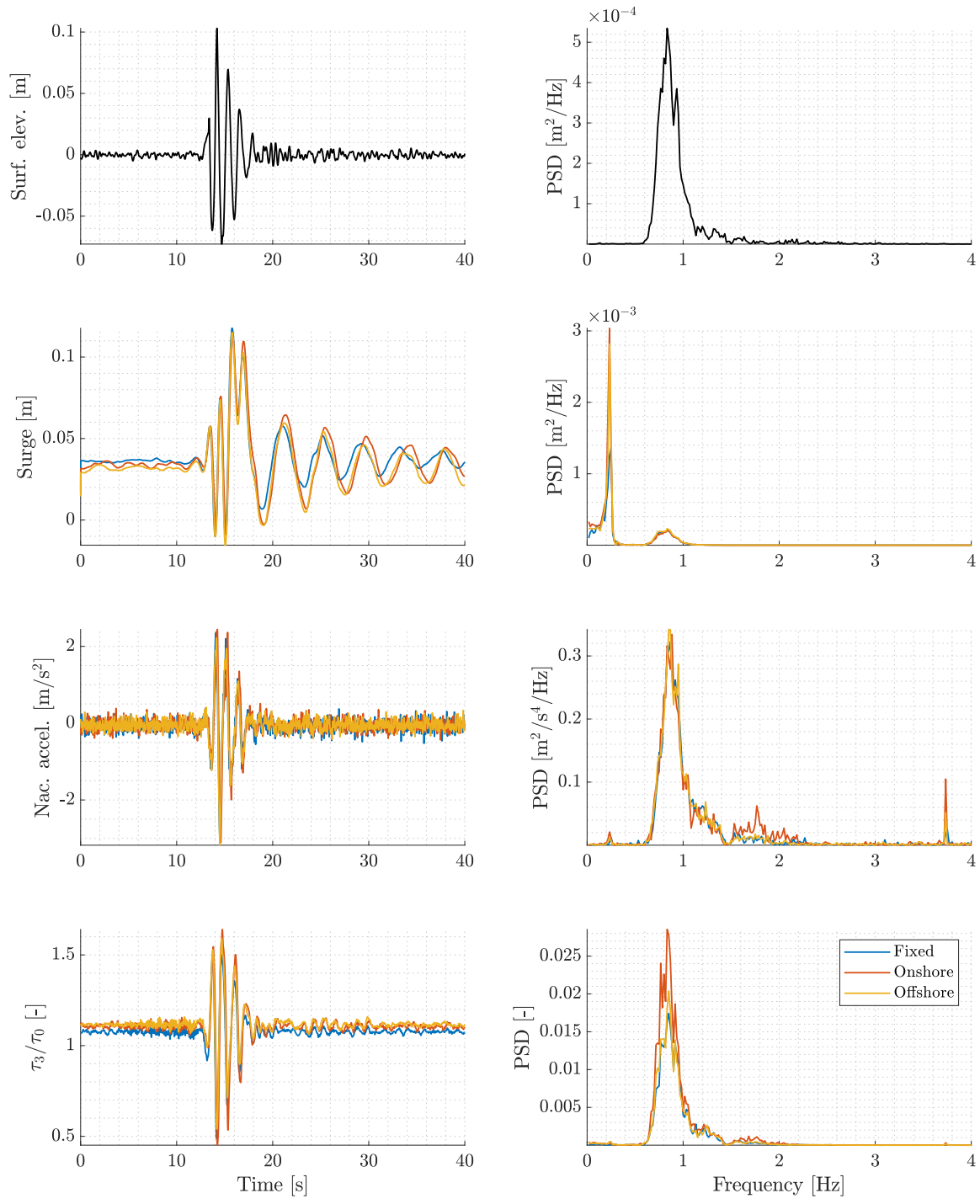

Figure 17: Surge response, nacelle fore-aft acceleration and normalised front mooring line tension for three different controllers in EC6 focused waves

As it can be seen, the impulsive excitation force from the focused wave group imposes a surge response of $0.12 \mathrm{~m}$ after the wave crest. It can be observed that the impact of the focused wave group causes a short sudden offset in the mean displacement of the surge motion, which is a nonlinear effect. After the focused wave group has passed, the structure decays back to equilibrium. This is why the surge motion is dominated by its own natural frequency of $0.24 \mathrm{~Hz}$ and with only minor energy at the wave frequency range. This is observed for all three controller configurations, but the damping (and thus energy level) of 
the decays are different. The fixed controller shows the strongest damping of the three configuration, which is due to the blade pitch is kept constant according to the mean wind speed, resulting in the largest positive damping. The onshore controller is less damped compared to the offshore controller, due to the fact that the natural frequency of offshore controller is reduced and thus less excitations at the surge natural frequency occur. This agrees well with onshore controller being able to excite instabilities when the controller is acting on one of the low frequency platform modes, as described in Section 4, leading to high surge response.

The nacelle acceleration responses for all three controllers are similar. From the corresponding power spectra it can be observed, that they are all dominated by the waves and have approximately the same level of energy at the wave frequency range. However, it is also clear that the motion of the onshore controller is further excited by the super harmonics at twice the wave peak frequency. Furthermore the $3 \mathrm{P}$ excitations at $3.89 \mathrm{~Hz}$ are significantly larger for the onshore compared to the other two and as for the surge motion lowest for the fixed configuration. This can be linked to the low level of damping for this controller.

Looking at the front mooring line tension, the onshore controller experiences the largest loads compared to the other two configurations. The maximum tension amplitude is increased with $3 \%$ compared to the offshore controller and $9 \%$ to the fixed configuration. It should also be pointed out that the mooring line tensions are dominated by the wave forcing and no significant excitations of the response natural frequencies are seen.

In Figure 18 the corresponding blade pitch and rotational speed of the turbine are presented. From the blade pitch the source of the increased mooring line tensions for the onshore can easily be seen, i.e. the severe reaction to the wind and waves. The blade pitch response for the onshore controller is dominated by the waves and the wind (shown by the peak furthest to the left), whereas the offshore controller is dominated by the surge natural frequency $(0.24 \mathrm{~Hz})$ and only very slightly excited by the waves.

Controlwise the results are very similar to the irregular wave case, only with enhanced excitations at the surge natural frequency, due to the decay after the impact of the focused wave group. 

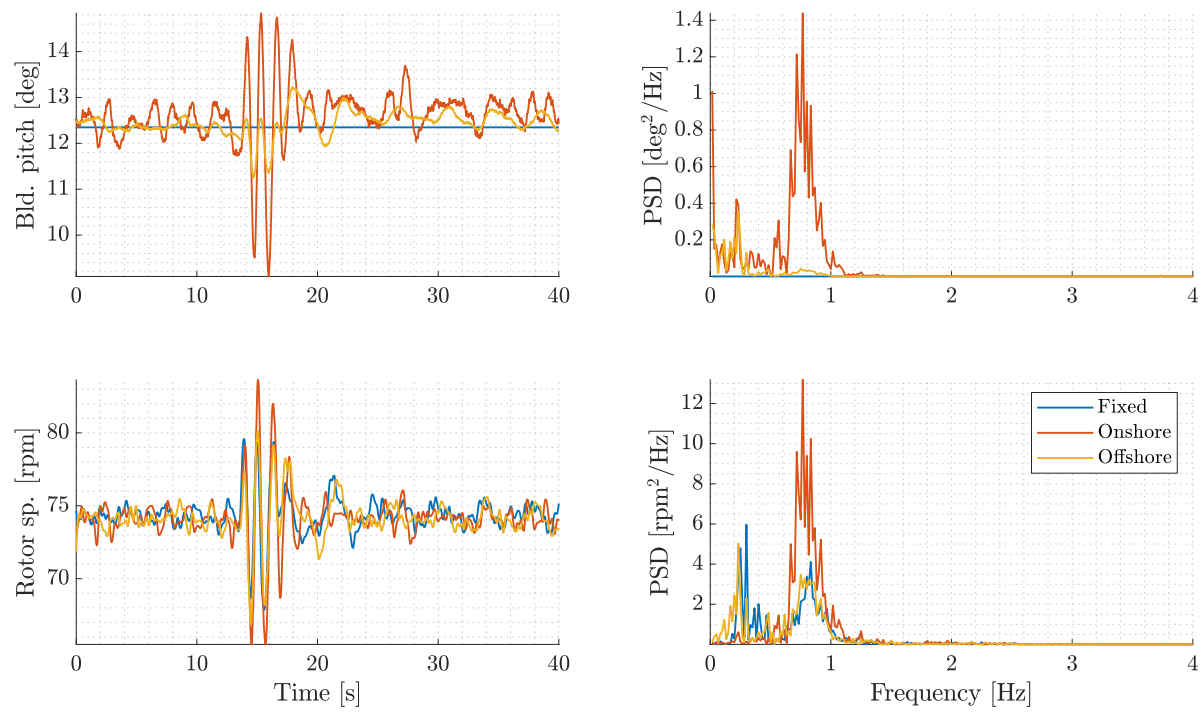

Figure 18: Turbine blade pitch and rotational speed for three different controllers in EC6 focused waves

\subsubsection{Turbine shutdown}

The impact of shutdown on the motion of the structure is investigated and the best way to see the impact is by using the extreme events, ie. the focused wave groups. The analysis is conducted with the the offshore controller configuration, and in the environmental case where the effect of wind is at maximum, hence rated wind speed, EC5. The shutdown of the controller was done manually and the aim was to have a shutdown at three diffeneret moments: i) before the highest crest of the focused wave group hit the structure, ii) at the very instant the wave crest breaks at the turbine position and iii) right after. In the following figures the labels Before, At and After refer to where the shutdown was executed relative to the wave peak. The procedure of the shutdown was so that the pitch was ramped from the instantaneous value to maximum pitch of $50 \mathrm{deg}$ with a rate of $15 \mathrm{deg} / \mathrm{s}$ (compared to the normal operation rate of 10 $\mathrm{deg} / \mathrm{s}$ ) and the generator torque set to zero.

Figure 19 presents the blade pitch angle $\theta_{p}$ and rotational speed $\Omega$ of the turbine for the shutdown cases. Due to the manual shutdown procedure it was very challenging to shutdown the turbine at the exact point of wave impact on the structure. It is evident from the blade pitch angle signal that the shutdown case at the point where the wave hit the turbine is actually a bit before. However, the test is still considered in the analysis. It is seen from the rotational speed that the rotor does not reach $0 \mathrm{rpm}$ after a shutdown. This is due to the maximum pitch angle being $50 \mathrm{deg}$ and the fact that the generator torgue is zero, causing an idle state of the turbine with a rotational speed of about 12 rpm in EC5. 

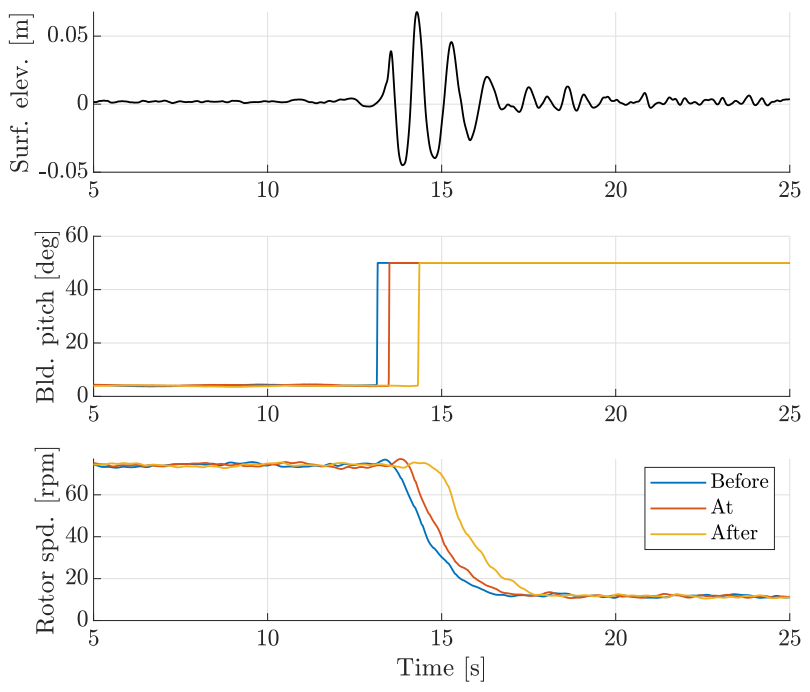

Figure 19: Wave elevation $\eta$, blade pitch angle $\theta_{p}$ and rotational speed $\Omega$ for the shutdown cases of the offshore controller in EC5 focused wave climate.

The corresponding motion response, in terms of surge motion, nacelle foreaft acceleration and normalised front mooring line tension, can be seen for the three shutdown cases in Figure 20. Furthermore, the black dashed lines in the plots represent the focused wave test where no shutdown was executed, but with the same controller. The highest surge response of nearly $-0.1 \mathrm{~m}$ is achieved in the case where the turbine is shutdown before the wave impact. This can be explained by the incoming trough forcing the turbine upwind and in the moment the shutdown appears, the loss of the thrust force acting on the rotor will cause the structure to experience a restoring force in the negative $x$-direction, resulting in an even greater surge displacement. The opposite effect is seen when the turbine is shutdown right after the break of the crest, where the surge displacement is damped. Releasing the thrust force will generate a high pitching moment and for the shutdowns before the wave impact, two major negative peaks can be observed, hence one from the shutdown and one from the wave peak. Only a slight increase in nacelle fore-aft acceleration can be observed, but the front mooring line, that is governed by the pitching motion, experiences very low tension when shutdown occur close to $\tau_{3} / \tau_{0}=0.5$. Approximately $33 \%$ decrease of the tension can be observed for shutdown before the wave impact compared to the case, where no shutdown is executed. 

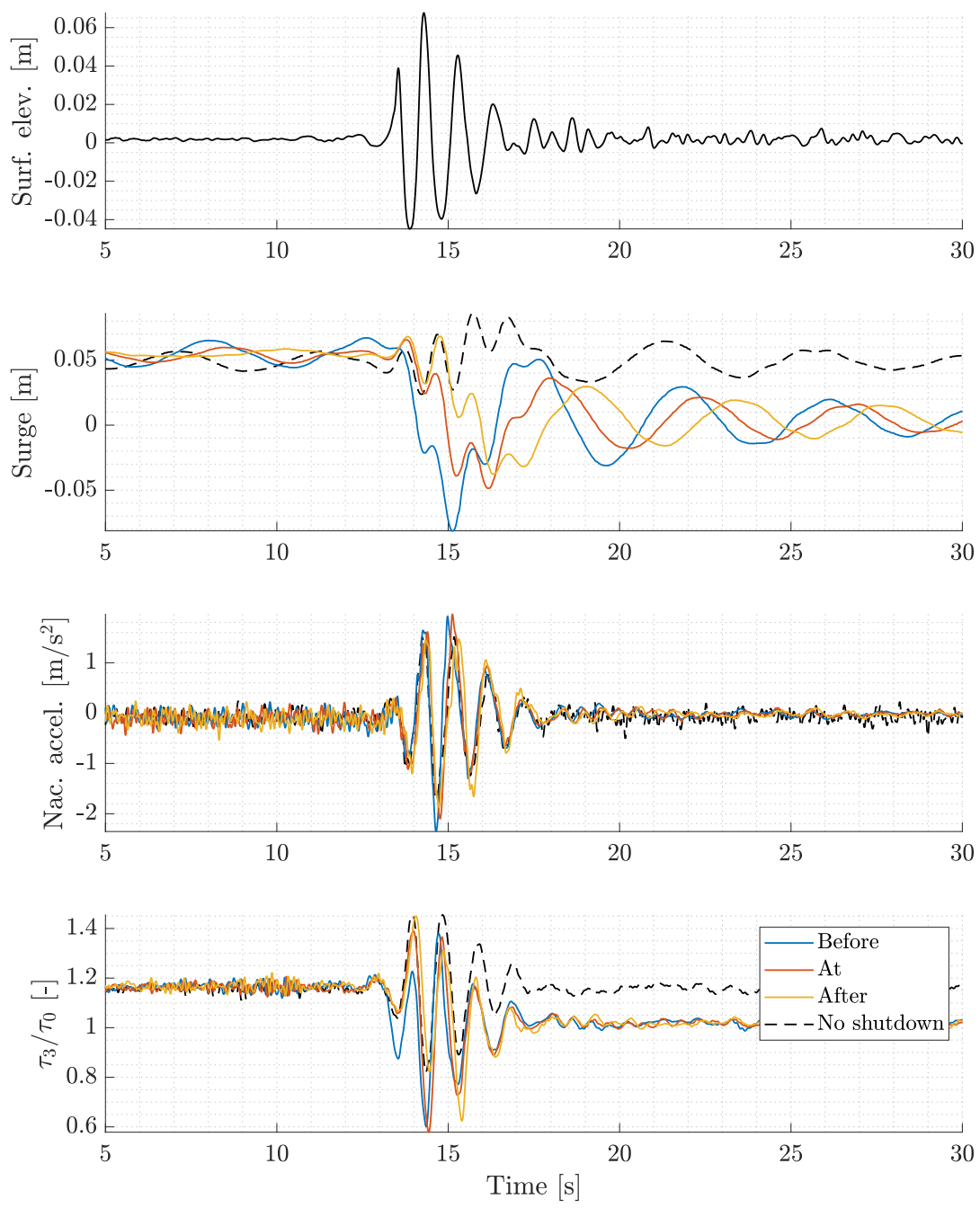

Figure 20: Surge response, nacelle fore-aft acceleration and normalised front mooring line tension for the shutdown cases of the offshore controller in EC5 focused wave climate.

\section{Conclusion}

The present work detailed the experimental testing of a Tension Leg Platform (TLP) substructure designed by the Korea Institute of Energy Research (KIER) and the pitch-regulated scaled 1/60 DTU $10 \mathrm{MW}$ reference wind turbine. The investigation included the response in regular waves, irregular waves, focused waves and a low turbulent wind field tested with different turbine controllers.

Before the wave tests, the aerodynamic performance of the fixed model scaled turbine was successfully tuned to match the down-scaled steady thrust curve of 
the $10 \mathrm{MW}$ reference turbine. The turbine was then mounted on the floater and free decay tests in still water provided insight of the structural natural frequencies and damping ratios.

Detailed analyses of the dynamic response of the three control configurations were carried out and it was observed that sensitivity of the onshore controller resulted in high oscillations in blade pitch, yielding an increased response in surge for all wave types. It was also observed that the surge motion governed the mooring line tensions, thus the onshore controller yielded the highest tensions in the front mooring line. Further the shutdown cases of the offshore controller led to larger surge displacement when the shutdown was initialized right before the wave impact. This was explained in terms of aerodynamic damping.

The present analysis demonstrates the potential of physical model testing, as part of the development of a new concepts. However physical model testing are also a crucial part of validating numerical models, which will be investigated as future work. This plays an important role in the design phase of floating support structures, both adding reliability to the design tools and confidence to the sector of floating wind turbines, and further ultimately pushing the offshore industry forward, thus bringing down the cost of offshore wind energy.

\section{Acknowledgements}

This work was conducted under framework of the research and development program of the Korea Institute of Energy Research (B6-2498) and supported by the Korea Institute of Energy Technology Evaluation and Planning (KETEP) and the Ministry of Trade, Industry \& Energy (MOTIE) of the Republic of Korea (no.20168520021200). Also the authors would like to thank Bjarne Jensen and Jesper Fuchs of DHI Denmark for the assistance provided for the duration of the experiments conducted in the DHI deep-water basin in Hørsholm, Denmark.

The published test data in the paper might be available by contacting the corresponding author.

\section{References}

[1] THE EUROPEAN PARLIAMENT, THE COUNCIL OF THE EUROPEAN UNION (2009). DIRECTIVE 2009/28/EC OF THE EUROPEAN PARLIAMENT AND OF THE COUNCIL of 23 April 2009 on the promotion of the use of energy from renewable sources and amending and subsequently repealing Directives 2001/77/EC and 2003/30/EC, Official Journal of the European Union.

[2] THE COUNCIL OF THE EUROPEAN UNION (2014). A POLICY FRAMEWORK FOR CLIMATE AND ENERGY IN THE PERIOD FROM 2020 TO 2030, ENVE-V-047, 108th plenary session, 6, 7 and 8 October 2014.

[3] Wind EUROPE (2019). Offshore Wind in Europe - Key trends and statistics 2018.

[4] CATAPULT Offshore Renewable Energy (2015). Floating wind: technology assessment. 
[5] James, R., Costa-Ros, M. (2015). Floating Offshore Wind: Market and Technology Review.

[6] James, R., Weng, W., Spradbery, C., Jones, J., Matha, D., Mitzlaff, A., Ahilan, R. V., Frampton, M., Lopes, M. (2018). Floating Wind Joint Industry Project Phase I summery report. CARBON TRUST. May 2018.

[7] Jonkman, J., Larsen, T., Hansen, A., Nygaard, T., Maus, K., Karimirad, M., Gao, Z., Moan, T., Fylling, I., Nichols, J., Kohlmeier, M., Pascual Vergara, J., Merino, D., Shi, W., Park, H. (2010). Offshore Code Comparison Collaboration within IEA Wind Task 23: Phase IV Results Regarding Floating Wind Turbine Modeling. European Wind Energy Conference (EWEC2010). Warsaw, Poland, April 20-23.

[8] Robertson, A., Jonkman, J., Vorpahl, F., Popko, W., Qvist, J., Frøyd, L., Chen, X., Azcona, J., Uzunoglu, E., Guedes Soares, C., Luan, C., Yutong, H., Pengcheng, F., Yde, A., Larsen, T., Nichols, J., Buils, R., Lei, L., Nygaard, T. A., Manolas, D., Heege, A., Vatne, S. R., Ormberg, H., Duarte, T., Godreau, C., Hansen, H. F., Nielsen, A. W., Riber, H., Le Cunff, C., Beyer, F., Yamaguchi, A., Jung, K. J., Shin, H., Shi, W., Park, H., Alves, M., Gurinel, M. (2014). Offshore Code Comparison Collaboration Continuation Within IEA Wind Task 30: PhaseII Results Regarding a Floating Semisubmersible Wind System. 33rd International Conference on Ocean,Offshore and Arctic Engineering, San Francisco, California, June 813.

[9] Goupee, A.J., Koo, B.J., Kimball, R.W., Lambrakos, K.F., Dagher, H.J. (2014). Experimental comparison of three floating wind turbine concepts. Journal of Offshore Mechanics and Arctic Engineering. 136(2): 020906.

[10] Martin, H. R., Kimball, R. W., Viselli, A. M., Goupee, A. J. (2014). Methodology for wind/wave basin testing of floating offshore wind turbines. Journal of Offshore Mechanics and Arctic Engineering; 136(2):020905.

[11] Karikomi, K., Ohta, M., Nakamura, A., Iwasaki, S., Hayashi, Y., Honda, A. (2015). Wind tunnel testing on negative-damped responses of a 7MW floating offshore wind turbine. Poster presented at EWEA Offshore 2015, Copenhagen.

[12] Hansen, A., Laugesen, R., Bredmose, H., Mikkelsen, R., Psichogios, N. (2014). Small scale experimental study of the dynamic response of a tension leg platform wind turbine. Journal of Renewable and Sustainable Energy. 6(5): 053108.

[13] Bredmose, H., Mikkelsen, R., Hansen, A., Laugesen, R., Heilskov, N., Jensen B., Kirkegaard, J. (2015). Experimental study of the DTU 10MW wind turbine on a TLP floater in waves and wind, Presented at the EWEA Offshore 2015 conference.

[14] Bredmose, H., Lemmer, F., Borg, M. B., Pegalajar-Jurado, A. M., Mikkelsen, R. F., Larsen, T. S., Fjelstrup, T., Yu, W., Lomholt, A. K., Boehm, L., Armendariz, J. A. (2017). The Triple Spar campaign: Model tests of a 10MW floating wind turbine with waves, wind and pitch control. Energy Procedia, 137, 58-76.

[15] Yu, W., Lemmer, F., Bredmose, H., Borg, M, Pegalajar-Jurado, A., Mikkelsen, R. F., Larsen, T. S., Fjelstrup, T., Lomholt, A. K., Boehm, L., Schlipf, D., Armendariz, J. A. (2017). The Triple Spar Campaign: Implementation and Test of a Blade Pitch Controller on a Scaled Floating Wind Turbine Model, ELSEVIER SCIENCE BV 
[16] Laugesen, R., Hansen, A. M. (2015). Experimental Study of the Dynamic Response of the DTU 10 MW Wind turbine on a Tension Leg Platform, Master's thesis, Department of Wind Energy, Technical University of Denmark, DK2800 Lyngby, Denmark DTU Wind Energy M-0065, Master Thesis Report.

[17] Mikkelsen, R. F. (2015). The DTU 10MW 1:60 model scale wind turbine blade, Tech. Rep., DTU Wind Energy.

[18] Hansen, M. H., Henriksen, L. C. (2013). Basic DTU Wind Energy controller, Tech. Rep., DTU Wind Energy.

[19] Bak, C., Zahle, F., Bitsche, R., Kim, T., Yde, A., Henriksen, L. C., Andersen, P. B., Natarajan, A., Hansen, M. H. (2013). Description of the DTU $10 \mathrm{MW}$ Reference Wind Turbine, Tech. Rep., DTU Wind Energy, Report-I-0092.

[20] Madsen, F. J., Nielsen, T. R. L. (2017). Experimental and numerical study of the scaled DTU 10MW floating wind turbine on a TLP platform, Master's thesis, Department of Wind Energy, Technical University of Denmark, DK2800 Lyngby, Denmark.

[21] Pegalajar-Jurado, A., Hansen, A. M., Laugesen, R., Mikkelsen, R. F., Borg, M., Kim, T., Heilskov, N. F., Bredmose, H. (2016). Experimental and numerical study of a 10MW TLP wind turbine in waves and wind. Journal of Physics: Conference Series (Online), 753, [092007].

[22] Bredmose, H., Larsen, S., Matha, D., Rettenmeier, A., Marino, E., Sættran, L. (2012). Collation of offshore windwave dynamics: Marine renewables infrastructure network for emerging energy technologies d2.4. Tech. Rep., DTU Wind Energy, deliverable of the Marinet project.

[23] Larsen, T. J., Hanson, T. D. (2007). A method to avoid negative damped low frequency tower vibrations for a floating pitch regulated wind turbine. Journal of Physics: Conference Series; 75(012073). The Science of Making Torque from Wind.

[24] Schløer, S., Bredmose, H., and Ghadirian, A. (2017). Analysis of experimental data: The average shape of extreme wave forces on monopile foundations and the NewForce model. Energy Procedia, 137, 223-237.

[25] P. S. Tromans, P. S., A. Anaturk, A., P. Hagemeijer, P. (1991). A new model for the kinematics of large ocean waves - application as a design wave, in: Proc. 1st Int. Conf. 708 Offsh. Mech. and Polar Engng. (ISOPE), Vol. 3, 1991, pp. 64-71. 